\title{
Phenyl saligenin phosphate induced caspase-3 and c-Jun N- terminal kinase activation in cardiomyocyte-like cells
}

Shatha Felemban, A. Christopher Garner, Fathi A. Smida, David J. Boocock ${ }^{1}$, Alan J. Hargreaves, John M. Dickenson*

School of Science and Technology

Nottingham Trent University

Clifton Lane

Nottingham

NG11 8NS

${ }^{1}$ John van Geest Cancer Research Centre,

Nottingham Trent University

Clifton Lane

Nottingham

NG11 8NS

*Author for correspondence; email: john.dickenson@ntu.ac.uk

Keywords: organophosphates, H9c2 cells, differentiation, caspase 3, phenyl saligenin phosphate, c-Jun N-terminal kinase 


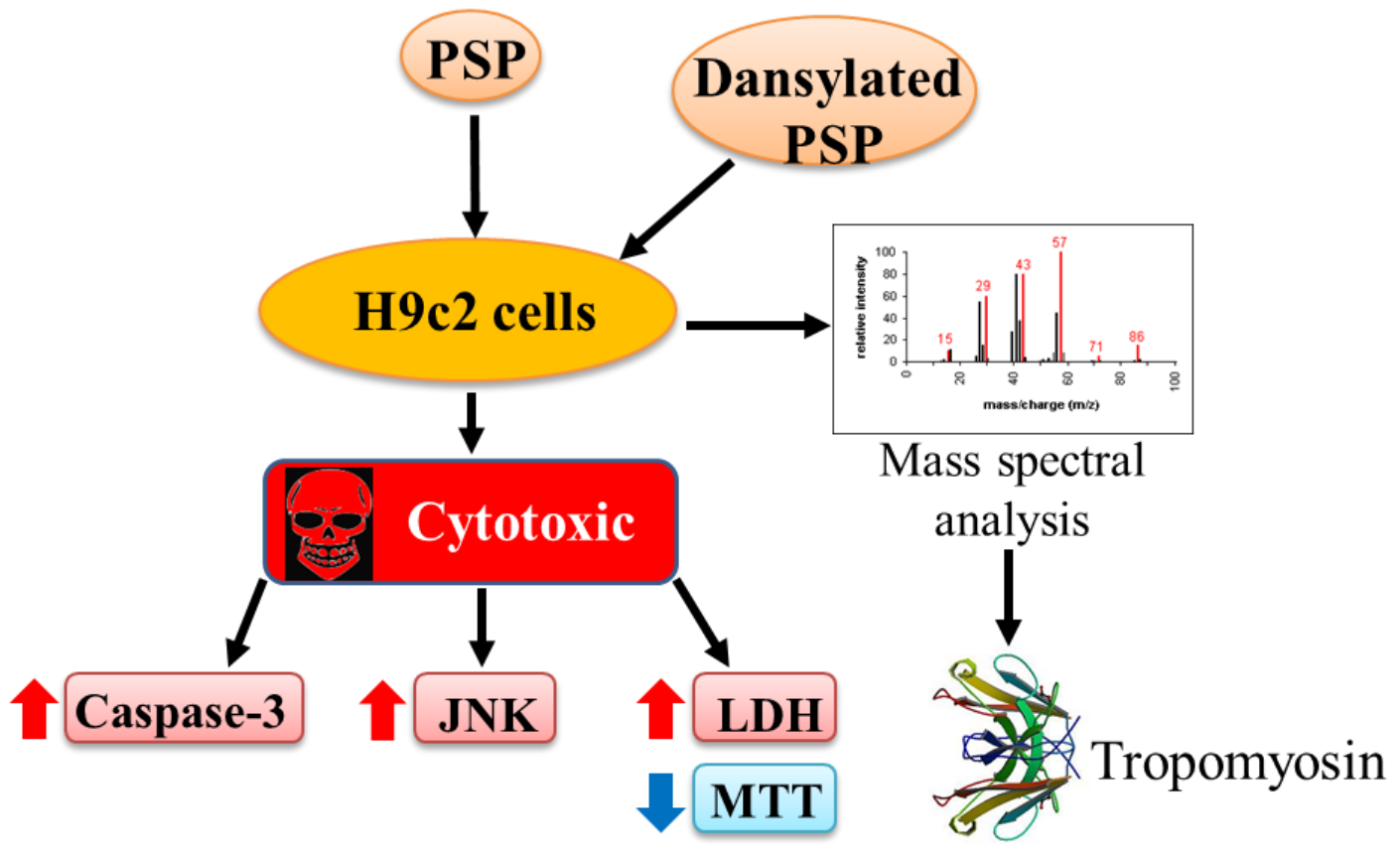




\section{ABSTRACT}

At present, little is known about the effect(s) of organophosphorous compounds (OPs) on cardiomyocytes. In this study we have investigated the effects of phenyl saligenin phosphate (PSP), two organophosphorothioate insecticides (diazinon and chlorpyrifos) and their acutely toxic metabolites (diazoxon and chlorpyrifos oxon) on mitotic and differentiated $\mathrm{H} 9 \mathrm{c} 2$ cardiomyoblasts. OP-induced cytotoxicity was assessed by monitoring MTT reduction, LDH release and caspase-3 activity. Cytotoxicity was not observed with diazinon, diazoxon or chlorpyrifos oxon (48 h exposure; $200 \mu \mathrm{M}$ ). Chlorpyrifos-induced cytotoxicity was only evident at concentrations $>100 \mu \mathrm{M}$. In marked contrast, PSP displayed pronounced cytotoxicity towards mitotic and differentiated H9c2 cells. PSP triggered the activation of JNK1/2, but not ERK1/2, p38 MAPK or PKB, suggesting a role for this pro-apoptotic protein kinase in PSP-induced cell death. The JNK1/2 inhibitor SP 600125 attenuated PSP-induced caspase-3 and JNK1/2 activation, confirming the role of JNK1/2 in PSP-induced cytotoxicity. Fluorescently labelled PSP (dansylated PSP) was used to identify novel PSP binding proteins. Dansylated PSP displayed cytotoxicity towards differentiated H9c2 cells. 2D-gel electrophoresis profiles of cells treated with dansylated PSP $(25 \mu \mathrm{M})$ were used to identify proteins fluorescently labelled with dansylated PSP. Proteomic analysis identified tropomyosin, heat shock protein $\beta-1$ and nucleolar protein 58 as novel protein targets for PSP. In summary, PSP triggers cytotoxicity in differentiated H9c2 cardiomyoblasts via JNK1/2-mediated activation of caspase-3. Further studies are required to investigate whether the identified novel protein targets of PSP play a role in the cytotoxicity of this OP, which is usually associated with the development of OP-induced delayed neuropathy. 


\section{INTRODUCTION}

Organophosphorous compounds (OPs) are widely used as insecticides (e.g. diazinon and chlorpyrifos) due to their ability to rapidly and irreversibly inhibit acetylcholinesterase (AChE) activity in neuromuscular junctions and the central nervous system. ${ }^{1-2}$ However, over-exposure can be fatal to non-target organisms including man. Some OPs are also extensively used as oil additives (e.g. tri-ortho-cresyl phosphate; TOCP) due to their ability to retain chemical properties under extreme conditions as in the case of aviation hydraulic fluids. ${ }^{3}$ The increased use of OPs over recent decades has heightened concerns about environmental pollution and food contamination, with numerous reports of human toxicity. Although the clinical effects of many OPs are linked to inhibition of AChE, damage to skeletal and cardiac muscle has been reported in studies of acute and chronic exposure. ${ }^{4-6}$ Hence, on-going research into OP-induced toxicity includes unravelling the molecular mechanisms underlying neurotoxicity and cardiotoxicity coupled with the identification of novel OP protein targets.

Regarding neurotoxicity, studies have shown that sub-acute exposure to some OPs is associated with various forms of delayed toxicity in non-target species. ${ }^{2}$ The clinical symptoms of one of these conditions, termed OP-induced delayed neuropathy (OPIDN), includes partial paralysis which appears 2-3 weeks following exposure to OPs such as TOCP. ${ }^{7-9}$ The molecular events responsible for OPIDN include inhibition of neuropathy target esterase (NTE), disruption of the axonal cytoskeleton ${ }^{7-9}$ and modulation of $\mathrm{Ca}^{2+}$ homeostasis. ${ }^{10-11}$ At present the majority of studies have focused on the effects of OPS on the central nervous system. There is very little information on the effect of OPs on muscle function, particularly toxic effects on cardiac muscle.

Previous studies have documented the cardiovascular consequences of acute OP poisoning, which include life-threatening ventricular arrhythmias and tachycardia. ${ }^{12-16}$ However, despite these well-known cardiac disturbances, very few studies have investigated the direct effects of OPs on cardiomyocyte function. A recent study explored the morphological changes in the rat heart following chronic treatment with a sub-lethal dose of the OP methamidophos, an insecticide used in many developed countries. ${ }^{17}$ 
Results indicated that repetitive doses of methamidophos induced cardiac muscle fibre hypertrophy, suggesting that OPs may interfere with cardiomyocyte physiology. Interestingly, electron microscope analysis of myocardial cells obtained from rats treated with diazinon revealed ultra-structural changes including vacuolisation and mitochondrial swelling, ${ }^{18}$ again suggesting that OPs can disrupt cardiomyocyte physiology via AChEindependent mechanisms.

The aim of the present study was to investigate the effect of OPs on the viability of mitotic and differentiated rat embryonic cardiomyoblast-derived H9c2 cells. ${ }^{19}$ These cells are used as an in-vitro model system since they display similar morphological, electrophysiological, and biochemical properties to primary cardiomyocytes. ${ }^{20}$ The OPs investigated were phenyl saligenin phosphate (PSP; an active congener of the OPIDNinducing metabolite of TOCP), two organophosphorothioate insecticides (diazinon and chlorpyrifos) and their acutely toxic metabolites (diazoxon and chlorpyrifos oxon). The results presented show that PSP, which is classed as a weak inhibitor of AChE, displays marked cytotoxicity towards differentiated H9c2 cells, whereas OPs classed as strong AChE inhibitors exhibited little or no cytotoxicity. Furthermore, PSP-induced cardiotoxicity appears to involve JNK1/2- mediated activation of caspase-3. 


\section{MATERIALS AND METHODS}

\section{Materials}

Chlorpyrifos, chlorpyrifos oxon, diazinon and diazoxon were purchased from Greyhound Chromatography and Allied Chemicals (Birkenhead, Merseyside, UK). Phenyl saligenin phosphate (PSP) and dansylated PSP were synthesised in house at Nottingham Trent University (Figure 1). All-trans retinoic acid was obtained from Sigma Chemical Co. (Poole, Dorset, UK). LY 294002, PD 98059, SB 203580, SP 600125 and wortmannin were obtained from Tocris Bioscience (Bristol, UK). Dulbeco's modified Eagle's Medium (DMEM), foetal calf serum, trypsin (10X), L-glutamine $(200 \mathrm{mM})$, penicillin $(10,000$ $\mathrm{U} / \mathrm{mL}) /$ streptomycin $(10,000 \mu \mathrm{g} / \mathrm{mL})$ were purchased from BioWhittaker UK Ltd. Antibodies were obtained from the following suppliers: monoclonal phospho-specific ERK1/2 (Thr202/Tyr 204; M8159) from Sigma-Aldrich Co. Ltd (Poole, UK); polyclonal phospho-specific PKB (Ser ${ }^{473} ;$ 9271), polyclonal total unphosphorylated PKB (9272), monoclonal total unphosphorylated ERK1/2 (9107), polyclonal total unphosphorylated JNK (9252), monoclonal phospho-specific JNK ( $\mathrm{Thr}^{183} / \mathrm{Tyr}^{185}$; 9251), polyclonal total unphosphorylated p38 MAPK (9212), monoclonal phospho-specific p38 MAPK (Thr ${ }^{180} /$ Tyr $^{182} ;$ 9216), and polyclonal anti- cleaved caspase-3 (9661) from New England Biolabs Ltd (Hitchin, UK). All other chemicals were of analytical grade. Stock solutions of OPs were diluted in DMSO, which was present in all treatments including the control at a final concentration of $0.5 \%(\mathrm{v} / \mathrm{v})$.

\section{Cell culture}

Rat embryonic cardiomyoblast-derived $\mathrm{H} 9 \mathrm{c} 2$ cells were obtained from the European Collection of Animal Cell Cultures (Porton Down, UK). Undifferentiated cells were cultured in DMEM supplemented with $2 \mathrm{mM}$ L-glutamine, $10 \%(\mathrm{v} / \mathrm{v})$ foetal calf serum and penicillin $(100 \mathrm{U} / \mathrm{mL}) /$ streptomycin $(100 \mu \mathrm{g} / \mathrm{mL})$. Cells were maintained in a humidified incubator $\left(95 \%\right.$ air $/ 5 \% \mathrm{CO}_{2}$ at $\left.37^{\circ} \mathrm{C}\right)$ until $70-80 \%$ confluent and sub-cultured (1:5 split ratio) using trypsin $(0.05 \% \mathrm{w} / \mathrm{v}) /$ EDTA $(0.02 \% \mathrm{w} / \mathrm{v})$. Differentiation of H9c2 cells was induced by culturing them for 7 days in DMEM supplemented with $1 \%(\mathrm{v} / \mathrm{v})$ FBS and $10 \mathrm{nM}$ all-trans 
retinoic acid. ${ }^{21-22}$ The medium was replaced every two days and differentiation into a more cardiomyocyte-like phenotype was confirmed by monitoring the expression of cardiac troponin 1 via immunocytochemistry and Western blotting. ${ }^{22-23}$

\section{Immunocytochemistry}

Activation of caspase 3 was assessed via immunocytochemical staining. H9c2 cells were seeded in 8-well chamber slides (BD Falcon ${ }^{\mathrm{TM}}$ CultureSlide) at a density of 15,000 cells/well and cultured for $24 \mathrm{~h}$, after which the medium was removed, replaced with differentiation medium and incubated for a further 7 days, changing the medium every two days. The medium was removed and adherent differentiated cells washed with phosphate buffered saline (PBS) pre-warmed to $37^{\circ} \mathrm{C}$. Cells were fixed with $3.7 \%(\mathrm{w} / \mathrm{v})$ paraformaldehyde (Sigma-Aldrich, UK) in PBS, for $15 \mathrm{~min}$ at room temperature without agitation and washed gently three times for $5 \mathrm{~min}$ with PBS. After fixation, permeabilisation was performed by incubating cells for 15 min at room temperature with $0.1 \%(\mathrm{v} / \mathrm{v})$ Triton $\mathrm{X}-100$ in PBS followed by washing three times for 5 min with PBS. Cells were incubated for $1 \mathrm{~h}$ at room temperature with $3 \%(\mathrm{w} / \mathrm{v})$ bovine serum albumin (BSA) in PBS (BSA/PBS) to prevent non-specific antibody binding. They were incubated overnight at $4^{\circ} \mathrm{C}$ in a humidified chamber with anti-cleaved caspase- 3 antibody $(1: 500)$ in BSA/PBS. Unbound primary antibody was then removed and the wells washed three times for $5 \mathrm{~min}$ with PBS. Cells were incubated for $2 \mathrm{~h}$ at $37^{\circ} \mathrm{C}$ in a humidified chamber with fluorescein isothiocyanate (FITC)-conjugated anti-mouse immunoglobulin G (Abcam, Cambridge, UK), diluted 1:1000 in 3\% (w/v) BSA in PBS. The chamber slide was subsequently washed three times for 5 min with PBS, air dried and mounted with Vectashield ${ }^{\circledR}$ medium (Vector Laboratories Ltd, Peterborough, UK) containing DAPI counterstain for nuclei visualisation. Finally slides were sealed using clear, colourless nail varnish and stained cells visualised using an Olympus DP71 epifluorescence microscope system equipped with an argon/krypton laser (FITC: EX493/Em528; DAPI: EX $360 /$ Em$_{460}$ ). 


\section{MTT assay}

Undifferentiated $\mathrm{H} 9 \mathrm{c} 2$ cells were plated in 24-well flat-bottomed plates at a final density of 15,000 cells/well and cultured for $24 \mathrm{~h}$ in fully supplemented DMEM. Cells were subsequently induced to differentiate for 7 days, as described above, prior to organophosphate treatment. Following organophosphate exposure cell viability was determined by measuring the metabolic reduction of MTT (3-(4-5-dimethylthiazol-2-yl)2,5-diphenyltetrazolium bromide) to a purple coloured formazan product. Briefly, cells were incubated for $1 \mathrm{~h}$ in $0.5 \mathrm{mg} / \mathrm{mL} \mathrm{MTT}$ (in the continued presence of OP) after which the medium was removed and replaced with $200 \mu \mathrm{L}$ DMSO. The magnitude of the reduction reaction was determined by monitoring the absorbance of the solubilised formazan product at $570 \mathrm{~nm}$.

\section{Lactate dehydrogenase assay}

H9c2 cells were plated in 96-well flat bottomed plates at a final density of 5,000 cells/well and cultured for $24 \mathrm{~h}$ in fully supplemented DMEM. Cells were subsequently induced to differentiate for 7 days prior OP treatment. Following OP exposure the activity of lactate dehydrogenase (LDH) released into the culture medium was detected colourimetrically using the CytoTox $96^{\circledR}$ Non-Radioactive Cytotoxicity assay (Promega, Southampton, UK). Assays were performed according to the manufacturer's instructions and changes in absorbance monitored at $490 \mathrm{~nm}$.

\section{Acetylcholinesterase assay}

H9c2 cells induced to differentiate for 7 days in $175 \mathrm{~cm}^{2}$ cell culture flasks were detached by trypsinisation and collected by centrifugation in ice cold PBS. They were resuspended in $0.1 \mathrm{M}$ phosphate buffer containing $0.2 \%(\mathrm{v} / \mathrm{v})$ Triton $\mathrm{X}-100$ and assayed for acetylcholinesterase activity, ${ }^{24}$ adapted for microtitre plate format. ${ }^{25}$ Absorbance change at $405 \mathrm{~nm}$ was linear over a $10 \mathrm{~min}$ period. Data were expressed as mean specific 
activity (absorbance change/min/mg protein) from at least three independent experiments.

\section{Western blot analysis of protein kinase phosphorylation and caspase 3 activation}

Analysis of protein kinase phosphorylation was performed using $\mathrm{H} 9 \mathrm{c} 2$ cells differentiated for 7 days in $25 \mathrm{~cm}^{2}$ tissue culture flasks. Following experimentation, cell supernatants were removed and the cells washed twice with $37^{\circ} \mathrm{C}$ PBS to remove serum proteins. A volume of $300 \mu \mathrm{L}$ of hot $\left(100^{\circ} \mathrm{C}\right)$ sodium dodecyl sulphate buffer $(0.5 \% \mathrm{w} / \mathrm{v}$ SDS in Tris buffered saline) was added and the resulting cell lysate boiled for 5 min prior to storage at $-20^{\circ} \mathrm{C}$. Protein concentration was determined using the Bio-Rad $D C^{\mathrm{TM}}$ Protein Assay kit (Bio-Rad laboratories, Hertfordshire, UK) with BSA as the standard.

Protein samples $(15 \mu \mathrm{g})$ were separated by sodium dodecyl sulphate/polyacrylamide gel electrophoresis (SDS/PAGE; $10 \%(\mathrm{w} / \mathrm{v})$ polyacrylamide gel) using a Bio-Rad MiniProtean III system. Proteins were transferred to nitrocellulose membranes using a BioRad Trans-Blot system ( $1 \mathrm{~h}$ at $100 \mathrm{~V}$ in $25 \mathrm{mM}$ Tris, $192 \mathrm{mM}$ glycine and $20 \% \mathrm{MeOH}$ ). Following transfer, the membranes were washed with Tris-buffered saline (TBS) and blocked for $1 \mathrm{~h}$ at room temperature in blocking buffer $(5 \%(\mathrm{w} / \mathrm{v})$ skimmed milk powder, $0.1 \%(\mathrm{v} / \mathrm{v})$ Tween-20 in TBS). Blots were incubated overnight at $4^{\circ} \mathrm{C}$ in blocking buffer with the following primary antibodies (1:1000 dilution unless otherwise indicated): phospho-specific ERK1/2, phospho-specific PKB (1:500), phospho-specific p38 MAPK, and phospho-specific JNK or cleaved active caspase 3 (1:500). The primary antibody was removed and the blot extensively washed three times for 5 min in TBS/Tween 20. Blots were then incubated for $1 \mathrm{~h}$ at room temperature with the appropriate secondary antibody (1:1000) coupled to horseradish peroxidase (DAKO Ltd, Cambridge, UK) in blocking buffer.

Following removal of the secondary antibody, blots were extensively washed as above developed using the Ultra Chemiluminescence Detection System (Cheshire Sciences Ltd, Chester, UK) and quantified by densitometry using Advanced Image Data Analysis 
Software (Fuji; version 3.52). The uniform transfer of proteins to the nitrocellulose membrane was routinely monitored by transiently staining the membranes with Ponceau S stain (Sigma-Aldrich Co. Ltd) prior to application of the primary antibody. In addition, replicate samples from each experiment were analysed on separate blots using total ERK1/2, PKB, p38 MAPK and JNK (all 1:1000 dilution) primary antibodies in order to confirm the uniformity of protein loading.

\section{D gel electrophoresis}

Two-dimensional gel electrophoresis was performed using differentiated H9c2 cells (7 days) cultured in $75 \mathrm{~cm}^{2}$ tissue culture flasks. Following experimentation, culture supernatants were removed and cells washed twice with warm PBS $\left(37^{\circ} \mathrm{C}\right)$ to remove serum proteins and lysed in $300 \mu \mathrm{L}$ urea lysis buffer ( $8 \mathrm{M}$ urea, $50 \mathrm{mM} \mathrm{DTT}, 4 \% \mathrm{w} / \mathrm{v}$ CHAPS, $0.2 \%$ v/v Bio-Lyte ${ }^{\circledR}$ 3/10 ampholyte; Bio-Rad, UK).

Samples (300 $\mu$ g protein) were applied onto ReadyStrip ${ }^{\mathrm{TM}}$ IPG strips (pH 3-10; Bio-Rad, UK) and passively rehydrated for $1 \mathrm{~h}$, then actively rehydrated for $16 \mathrm{~h}$ at $50 \mathrm{~V}$ followed by IEF ( $250 \mathrm{~V}$ for $20 \mathrm{~min}$ linear, $400 \mathrm{~V}$ for $2 \mathrm{~h}$ linear, $4000 \mathrm{~V}$ for $10,000 \mathrm{~V} / \mathrm{h}$ rapid; slope down to $500 \mathrm{~V}$ for $25 \mathrm{~h}$ ) using a PROTEAN IEF cell (Bio-Rad, UK). Strips were transferred to equilibration buffer (6 M urea, 2\% (w/v) SDS, 50\% (v/v) glycerol, 2\% $(\mathrm{w} / \mathrm{v}) \mathrm{DTT}, 1.5 \mathrm{M} \mathrm{Tris} / \mathrm{HCl} \mathrm{pH} 8.8$, ) for $10 \mathrm{~min}$ followed by a further $10 \mathrm{~min}$ in $2.5 \%$ $(w / v)$ iodoacetamide in equilibration buffer. Following equilibration, IPG strips were subjected to SDS-PAGE in a $15 \%(\mathrm{w} / \mathrm{v})$ polyacrylamide gel using a Bio-Rad Mini-Protean III system. After electrophoresis, gels were visualised and dansylated-PSP labelled proteins visualised under UV light (Syngene G-box) and then stained for $16 \mathrm{~h}$ using ProtoBlue $^{\mathrm{TM}}$ safe colloidal Coomassie G-250 stain (Bio-Rad, UK) and photographed using a Syngene G-box with GeneSnap software (version 7.12.06). Images were analysed using Progenesis SameSpots (V 3.1.3030.23662) software (Nonlinear Dynamics, UK). 


\section{Mass Spectrometry analysis}

Selected spots were excised from the gel and dehydrated in acetonitrile for $5 \mathrm{~min}$ at $37^{\circ} \mathrm{C}$ under gentle agitation, rehydrated in $25 \mathrm{mM} \mathrm{NH}_{4} \mathrm{HCO}_{3}$ for $10 \mathrm{~min}$, and sequentially dehydrated, rehydrated and dehydrated. The gel pieces were incubated with mass spectrometry grade trypsin (Trypsin Gold; Promega; $0.55 \mu \mathrm{g}$ per spot in $25 \mu \mathrm{l}$ of 66.4 $\mathrm{mM}$ ammonium bicarbonate) for $16 \mathrm{~h}$ at $37^{\circ} \mathrm{C}$ after which the reaction was terminated by adding $1 \% \mathrm{v} / \mathrm{v}$ trifluoroacetic acid (TFA). After tryptic digestion, peptides were desalted and concentrated prior to MALDI-TOF mass spectrometry using $C_{18}$ ZipTips (200 pore size; Millipore, UK). Finally, $1.5 \mu \mathrm{L}$ of the peptide digest was spotted onto a MTP 384 Ground Steel MALDI target plate (Bruker; Germany) together with $1.5 \mu \mathrm{L}$ of 5 $\mathrm{mg} / \mathrm{mL}$ a-cyano-4-hydroxycinnamic acid ( $\mathrm{CHCA}$ ) matrix mixture (Bruker Daltonics, UK) in $50 \%(\mathrm{v} / \mathrm{v})$ acetonitrile, $0.1 \%(\mathrm{v} / \mathrm{v})$ TFA. Peptides were analysed using a Bruker UltrafleXtreme ${ }^{\mathrm{TM}}$ MALDI-TOFTOF mass spectrometer (reflectron positive mode, ion suppression $m / z$ 650, mass range $m / z$ 0-4000). Proteins were identified using BrukerDaltonics Biotools (v 3.2, build 2.3) software, searched against SwissProt database, rat species, using Mascot (version 2.3 server, Matrix Science, UK), PMF 100 ppm tolerance and reported according to percentage sequence coverage (SC\%). MS/MS search parameters; MS tolerance $100 \mathrm{ppm}$, MS/MS tolerance $0.8 \mathrm{Da}$, three missed cleavages. All identified proteins exhibited Mascot scores which were considered statistically significant $(p<0.05)$.

\section{Binding of dansylated PSP to purified tropomyosin}

To validate the identification of one of the proteins labelled by dansylated PSP, purified human heart tropomyosin (10 $\mu$; Lee Biosolutions, USA) was incubated for $1 \mathrm{~h}$ with 25 $\mu \mathrm{M}$ dansylated PSP or un-labelled PSP. The purified tropomyosin was subjected to SDSPAGE on a $10 \%(\mathrm{w} / \mathrm{v})$ polyacrylamide gel and fluorescence visualised under UV light. 


\section{Data analysis}

Unless otherwise specified, statistical significance was determined by ANOVA with a post hoc Tukey test $\left(p<0.05\right.$ was considered statistically significant). Organophosphate IC $_{50}$ values (concentrations of drug producing $50 \%$ of the maximal inhibition) derived from MTT assays and $\mathrm{EC}_{50}$ values (concentrations of drug producing $50 \%$ of the maximal stimulation) derived from LDH assays were obtained by computer assisted curve fitting using Prism software (GraphPAD version 6, California, USA). All data are presented as means \pm S.E.M. The $n$ in the text refers to the number of separate experiments. The number of replicates within each experiment is indicated, were appropriate, in the Figure legend. 


\section{RESULTS}

\section{Effects of organophosphates on the viability of mitotic H9c2 cells}

$\mathrm{H} 9 \mathrm{c} 2$ cells are derived from embryonic rat heart tissue ${ }^{19}$ and have been used widely as an in vitro model, since they display similar morphological, electrophysiological and biochemical properties to primary cardiac myocytes. ${ }^{20}$ Initial experiments investigated the effects of OPs on the viability of mitotic H9c2 cells, which display properties of skeletal muscle. The effects of OP treatment on cell viability were assessed by monitoring MTT reduction (a measure of cellular dehydrogenase activity) and measurement of LDH activity released into the culture medium. At concentrations of up to $200 \mu \mathrm{M}$ both diazinon and its acutely toxic metabolite diazoxon had no significant effect on MTT reduction or LDH release following $48 \mathrm{~h}$ exposure (data not shown). Chlorpyrifos at $200 \mu \mathrm{M}$ and $100 \mu \mathrm{M}$ inhibited MTT reduction following $24 \mathrm{~h}$ and $48 \mathrm{~h}$ exposure (Figure 2) but had no effect on LDH release at these time points (data not shown). In contrast, chlorpyrifos oxon at concentrations up to $200 \mu \mathrm{M}$ had no significant effect on MTT reduction or LDH release after $48 \mathrm{~h}$ exposure (data not shown).

Phenyl saligenin phosphate (PSP; an active congener of the OPIDN-inducing metabolite of TOCP) significantly inhibited the reduction of MTT and triggered the release of LDH following $24 \mathrm{~h}$ and $48 \mathrm{~h}$ treatment (for clarity data not shown). Subsequent experiments assessed the effects of PSP on MTT reduction and LDH release at earlier time points e.g. $1,2,4$, and $8 \mathrm{~h}$ (Figure 3). The data from these experiments revealed that PSP-induced inhibition of MTT reduction was first evident at $4 \mathrm{~h}$ ( $\left.\mathrm{IC}_{50}=8.5 \pm 5.5 \mu \mathrm{M}\right)$, with comparable results obtained at $8 \mathrm{~h}$ exposure $\left(\mathrm{IC}_{50}=7.1 \pm 4.7 \mu \mathrm{M}\right)$. Similarly, significant $\mathrm{LDH}$ release was first evident at $4 \mathrm{~h}\left(\mathrm{EC}_{50}=13 \pm 1.1 \mu \mathrm{M}\right)$ and at $8 \mathrm{~h}\left(\mathrm{EC}_{50}=13 \pm 1.5\right.$ $\mu \mathrm{M})$, with levels of LDH release comparable to those observed following $24 \mathrm{~h}$ treatment All IC $_{50}$ and $\mathrm{EC}_{50}$ plots are shown in Supplementary data Figure 1. Overall, these data indicate that PSP displays marked cytotoxicity towards mitotic H9c2 cells. 


\section{Effects of organophosphates on the viability of differentiated H9c2 cells}

Mitotic H9c2 cells can be differentiated into a more cardiomyocyte-like phenotype by culturing the cells for 7 days in DMEM supplemented with $1 \%(\mathrm{v} / \mathrm{v})$ FBS and $10 \mathrm{nM}$ all-trans retinoic acid. ${ }^{21-22}$ Therefore, we investigated the effects of OPs on the viability of differentiated $\mathrm{H} 9 \mathrm{c} 2$ cells. H9c2 differentiation was confirmed by monitoring the expression of cardiac troponin 1 by immunocytochemistry and Western blotting (data not shown) as originally described by Comelli et al. ${ }^{22}$ and confirmed in-house. ${ }^{23}$ At concentrations up to $200 \mu \mathrm{M}$, both diazinon and diazoxon had no significant effect on MTT reduction or LDH release following $48 \mathrm{~h}$ exposure (data not shown). Chlorpyrifos at $200 \mu \mathrm{M}$ and $100 \mu \mathrm{M}$ inhibited MTT reduction following 24 and $48 \mathrm{~h}$ exposure and at $200 \mu \mathrm{M}$ triggered a small but significant release in LDH at these time points (Figure 4). In contrast, chlorpyrifos oxon at concentrations up to $200 \mu \mathrm{M}$ had no significant effect on MTT reduction or LDH release after $48 \mathrm{~h}$ exposure (data not shown).

In differentiated cells, PSP significantly inhibited the reduction of MTT and triggered the release of LDH following $24 \mathrm{~h}$ and $48 \mathrm{~h}$ treatment (for clarity, data not shown). Subsequent experiments assessed the effects of PSP on MTT reduction and LDH release at earlier time points e.g. 1, 2, 4, and $8 \mathrm{~h}$ (Figure 5). The data from these experiments revealed that PSP-induced inhibition of MTT reduction was first evident at $2 \mathrm{~h}\left(\mathrm{IC}_{50}=6.5\right.$ $\pm 1.2 \mu \mathrm{M})$, with further inhibition observed following $4 \mathrm{~h}\left(\mathrm{IC}_{50}=12.8 \pm 4.9 \mu \mathrm{M}\right)$ and $8 \mathrm{~h}$ $\left(\mathrm{IC}_{50}=25 \pm 9.3 \mu \mathrm{M}\right)$ exposure. In contrast, $\mathrm{LDH}$ release was first evident at $4 \mathrm{~h}\left(\mathrm{EC}_{50}=\right.$ $15.8 \pm 6.1 \mu \mathrm{M})$ and increased at $8 \mathrm{~h}\left(\mathrm{EC}_{50}=15.1 \pm 4.3 \mu \mathrm{M}\right)$, when levels of $\mathrm{LDH}$ release were comparable to those observed following $24 \mathrm{~h}$ treatment. $\mathrm{All}_{\mathrm{II}} \mathrm{IC}_{50}$ and $\mathrm{EC}_{50}$ plots are shown in Supplementary data Figure 2. Overall, these data indicate that PSP induces cytotoxicity in differentiated H9c2 cells. However, it should be noted that $100 \%$ cell death was not achieved at any OP concentration or exposure time point. This could be due to a gradual loss of OP over time, for example due to serum protein binding or inactivation by enzymic and/or non-enzymic pathways. As the OPs used are hydrophobic they may also come out of solution at higher concentrations and longer exposure times, thus negating their potential to kill all of the cells. 
Whilst MTT reduction and LDH release and are widely used markers of cell viability, they do not discriminate between apoptotic and necrotic forms of cell death. To assess whether PSP-induced cell death involved apoptosis, we measured caspase-3 activation following PSP treatment. Caspase-3 activation was initially monitored by Western blotting using an antibody that recognises the large fragments (17/19 kDa) of activated caspase-3. As evident in Figure 6A, treatment of differentiated H9c2 cells with $25 \mu \mathrm{M}$ PSP for $4 \mathrm{~h}$ triggered a significant increase in caspase-3 activation. Similar results were obtained when PSP-induced caspase-3 activation was monitored via immunocytochemistry (Figure 6B).

In order to establish the relationship between the above cytotoxic effects and the level of AChE activity, cholinesterase assays were performed in the presence and absence of PSP. As can be seen in Figure 7, PSP was a very weak inhibitor of AChE activity in H9c2 cells, with exposure to $25 \mu \mathrm{M}$ causing only approximately $30 \%$ inhibition compared to control levels of activity. Additional experiments (data not shown) indicated much stronger inhibition of AChE by chlorpyrifos oxon.

\section{Effects of PSP on protein kinase phosphorylation}

PSP-induced cell death in mitotic and differentiated H9c2 cells may involve the modulation of pro-survival and/or pro-apoptotic signalling pathways. It is generally accepted that extracellular signal-regulated kinases 1 and $2($ ERK1/2) and protein kinase $B$ (PKB; also known as Akt) activation promotes cell survival by activating anti-apoptotic signalling pathways, whereas the activation of c-Jun N-terminal kinases (JNK) and p38 mitogen-activated protein kinases (p38 MAPK) are associated with apoptotic cell death. ${ }^{26-27}$ PSP-induced modulation of protein kinase activity was assessed by Western blotting using phospho-specific antibodies that recognise phosphorylated motifs within activated ERK1/2 (pTEpY), p38 MAPK (pTGpY), JNK (pTPpY) and PKB ( $\left.{ }^{473}\right)$. Treatment of differentiated H9c2 cells for $1 \mathrm{~h}, 2 \mathrm{~h}, 4 \mathrm{~h}$ and $8 \mathrm{~h}$ with PSP $(25 \mu \mathrm{M})$ had no significant effect on the levels of phosphorylated ERK1/2, p38 MAPK or PKB (data not shown). In marked 
contrast, PSP $(25 \mu \mathrm{M})$ induced a time-dependent increase in JNK1/2 activation in differentiated H9c2 cells (Figure 8).

\section{Role of protein kinases in PSP-induced cell death}

To investigate the further the role of JNK1/2 in PSP-induced cell death, differentiated H9c2 cells were pre-treated for 30 min with the JNK1/2 inhibitor SP $600125(10 \mu \mathrm{M}){ }^{28}$ prior to OP exposure. As shown in Figure 9, SP 600125 had no significant effect on 25 $\mu \mathrm{M}$ PSP-induced inhibition of MTT reduction or LDH release following $4 \mathrm{~h}$ or $8 \mathrm{~h}$ OP exposure. Western blot analysis was subsequently used to establish whether SP 600125 $(10 \mu \mathrm{M})$ attenuates PSP-induced JNK1/2 activation in H9c2 cells. As depicted in Figure 10, SP 600125 significantly inhibited PSP $(25 \mu \mathrm{M})$-induced JNK1/2 activation following $1 \mathrm{~h}$ and 2 h OP exposure. However, SP 600125 did not block PSP-induced JNK1/2 activation after $4 \mathrm{~h}$ of exposure, which presumably accounts for the lack of effect observed with SP 600125 when monitoring PSP-induced inhibition of MTT reduction and release of LDH at $4 \mathrm{~h}$ and $8 \mathrm{~h}$ (Figure 9). Since PSP-induced caspase-3 activation was evident at $1 \mathrm{~h}$ and 2 h OP exposure, we determined the effect of SP 600125 on PSP-induced caspase-3 activation at these earlier time points via immunocytochemistry. As shown in Figure 11, SP $600125(10 \mu \mathrm{M})$ attenuated PSP-induced caspase-3 activation confirming the involvement of JNK1/2 in PSP-mediated cell death in H9c2 cells. For comparison the

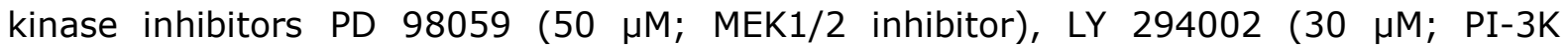
inhibitor), wortmannin (100 nM; PI-3K inhibitor), and SB 203580 (30 $\mu \mathrm{M}$; p38 MAPK inhibitor) had no significant effect on PSP-induced caspase-3 activation (data not shown).

\section{Identification of PSP binding proteins}

The results presented thus far indicate that PSP triggers cell death in H9c2 cells via JNK1/2 activation. In order to explore further the mechanism(s) of PSP-induced cytotoxicity we carried out studies using fluorescently labelled PSP (dansylated PSP) in 
order to identify novel PSP binding proteins. Initial experiments confirmed that dansylated PSP caused similar levels of cytotoxicity as PSP in differentiated H9c2 cells (Figure 12). Identification of dansylated PSP labelled proteins was achieved by 2D-gel electrophoresis of cell lysates obtained from cells treated with dansylated PSP ( $1 \mathrm{~h}, 25$ $\mu \mathrm{M}$; see Figure 13) followed by MALDI-TOF analysis of the peptides produced by trypsin digestion. Mass spectrometry analysis identified tropomyosin, heat shock protein 27 and nucleolar protein 58 as novel protein targets for PSP (Table 1). Tropomyosin was chosen for validation by incubation of purified human tropomyosin with dansylated PSP, followed by visualisation using SDS-PAGE. The data shown in Figure 14, confirmed that tropomyosin was labelled by dansylated PSP in H9c2 cells. 


\section{DISCUSSION}

At present there is very little information on the direct effect of OPs on muscle function and, in particular, their toxic effects on cardiomyocytes. In this study we investigated the effect of OPs on mitotic and differentiated $\mathrm{H} 9 \mathrm{c} 2$ cardiomyoblasts. Initial experiments examined chlorpyrifos and diazinon and their in vivo metabolites diazoxon and chlorpyrifos oxon. Cytotoxicity was not observed with diazinon, diazoxon or chlorpyrifos oxon (48 h exposure; $200 \mu \mathrm{M}$ ), whereas chlorpyrifos-induced cytotoxicity was only evident at concentrations $>100 \mu \mathrm{M}$. These results are in stark contrast to the cardiovascular consequences of acute OP poisoning, which reflects over-activity of sympathetic and parasympathetic pathways due to enhanced levels of acetylcholine. ${ }^{12-16}$ In summary, OPs that mediate acute in vivo toxicity, primarily via AChE inhibition, display little cytotoxicity towards H9c2 cardiomyoblasts. In marked contrast, PSP displayed pronounced cytotoxicity towards mitotic and differentiated H9c2 cells. PSP is an analogue of saligenin cyclic-o-tolyl phosphate (SCOTP), the in vivo metabolite of TOCP, and is classed as a weak inhibitor of AChE. ${ }^{29}$ Hence the cytotoxic effects of PSP observed in this study are presumably mediated via non-cholinergic mechanisms. The data from AChE activity assays confirm the weak effect of PSP on cholinesterase activity under the same experimental conditions, indicating that acute effects on AChE were not involved. However, it is important to note PSP is a potent inhibitor of butyrylcholinesterase, the activity of which is higher than acetylcholinesterase in rat heart. ${ }^{30-31}$ Hence, in future work it would be of interest to monitor the effect of PSP on butyrylcholinesterase activity in $\mathrm{H} 9 \mathrm{c} 2$ cells.

PSP is used in neuronal cell models investigating the molecular targets responsible for OP-induced delayed neuropathy (OPIDN), a condition associated with OPs such as TOCP. ${ }^{7-9}$ TOCP is an isomer of tricresyl phosphate (TCP), an OP with a wide range of applications due to its flame retardant and lubricant properties. ${ }^{32}$ For example, it is used in the aviation industry as a fuel and hydraulic fluid additive but also as a plasticiser, waterproofing agent and solvent. Since isomers of TCP have been detected in air cabins 
and cockpits on commercial and military aircraft, it has been suggested that OP poisoning may be involved in the phenomenon of air cabin sickness. ${ }^{33}$ At present the cellular effect(s) of neuropathic OPs, such as PSP, on cardiomyocytes are largely unknown.

\section{Mechanisms of PSP-induced cytotoxicity}

In this study we initially assessed PSP-induced cytotoxicity by monitoring MTT reduction and LDH release. It is notable that PSP-induced toxicity was evident at $2 \mathrm{~h}$ when monitoring MTT reduction, whereas PSP toxicity assessed by LDH release was first detectable at $4 \mathrm{~h}$. The difference in sensitivity between MTT and LDH assays is in agreement with previous studies, which have reported the MTT assay as being more sensitive in detecting cytotoxic events. ${ }^{34}$ Treatment with PSP $(25 \mu \mathrm{M})$ also triggered the rapid activation of caspase 3, suggesting that PSP-induced cytotoxicity involves apoptotic cell death. These cytotoxic effects are consistent with previous studies showing that PSP triggers a decrease in MTT reduction in mouse N2a neuroblastoma and human hepatic HepG2 cells (IC 50 values of approximately $10-15 \mu \mathrm{M}),{ }^{35}$ and activation of caspase 3 in SH-SY5Y human neuroblastoma cells $(10$ and $100 \mu \mathrm{M}) .{ }^{36}$ The IC 50 values for PSP-induced toxicity obtained in this study (circa 10-20 $\mu \mathrm{M}$ ) are comparable to those reported in N2a and HepG2 cells. ${ }^{35}$

In order to understand more clearly the mechanism(s) of PSP-induced cytotoxicity, the effect of PSP exposure on protein kinase cascades associated with cell survival (ERK1/2 and PKB) and cell death (p38 MAPK and JNK) was investigated. In view of their respective roles in cell death and cell survival, it would be predicted that PSP-induced cytotoxicity may involve attenuation of ERK1/2 and PKB signalling and/or activation of p38 MAPK and JNK. PSP did not significantly modulate ERK1/2, p38 MAPK or PKB phosphorylation status in differentiated H9c2 cells. However, PSP $(25 \mu \mathrm{M})$ triggered a robust and time-dependent activation of JNK1/2. These data are in agreement with previous studies that have reported the modulation of protein kinase signalling by sub-lethal concentrations of PSP. For 
example, PSP triggered activation of ERK1/2 in mouse N2a neuroblastoma cells $(2.5 \mu \mathrm{M} ; 4$ h) ${ }^{37}$ and activation of PKB in human SH-SY5Y neuroblastoma cells $(0.1 \mu \mathrm{M}) .{ }^{38}$ It is notable that the effect of PSP on PKB activation in SH-SY5Y cells was a consequence of OP-induced activation of the low affinity neurotrophin p75 receptor. ${ }^{38}$ Further studies are required in order to elucidate the molecular mechanism(s) of PSP-induced JNK1/2 activation in differentiated H9c2 cells.

To verify the role of JNK1/2, we determined the effect of the $J N K 1 / 2$ inhibitor SP 600125 on PSP-induced inhibition of MTT reduction and release of LDH. Pre-treatment with SP 600125 had no significant effect on $25 \mu \mathrm{M}$ PSP-induced inhibition of MTT reduction or LDH release following $4 \mathrm{~h}$ or $8 \mathrm{~h}$ OP exposure. However, subsequent experiments revealed that, whilst SP 600125 attenuated PSP-induced JNK1/2 activation following $1 \mathrm{~h}$ and $2 \mathrm{~h}$ PSP exposure, it was ineffective at blocking PSP-induced JNK1/2 activation at $4 \mathrm{~h}$. These observations presumably account for the lack of effect of SP 600125 when assessing cell viability at $4 \mathrm{~h}$ and $8 \mathrm{~h}$ time points, using MTT and LDH assays. The reversible inhibition of PSP-induced JNK1/2 activation by SP 600125 may reflect removal of the inhibitor from the cell (although the inhibitor was present throughout the experiment) and/or metabolism to an inactive metabolite. However, SP 600125 did block caspase 3 activation at $1 \mathrm{~h}$ confirming the involvement of JNK $1 / 2$ in PSP-induced apoptosis. It is interesting to note that although SP 600125 blocked caspase 3 activation at $4 \mathrm{~h}$, it did not block PSP-induced JNK1/2 activation at $4 \mathrm{~h}$. This is presumably a consequence of caspase 3 activation being downstream of JNK1/2 and hence inhibition of JNK1/2 at early time points $(<2 h)$ prevents subsequent caspase 3 activation.

In terms of the clinical relevance of our data, similar levels of neurodegenerative metabolite saligenin cyclic -o-tolyl phosphate (of which PSP in a structural analogue) are more likely to be achieved in heart tissue after deliberate or accidental exposure to significant amounts of tri-ortho-cresyl phosphate, than via normal levels of occupational exposure. However, given that the activation of caspase-3 occurs within the first hour of 
exposure to $25 \mu \mathrm{M}$ PSP, it is possible that such levels could be achieved only transiently in vivo. In this respect it is interesting to note that levels of more than $100 \mu \mathrm{M}$ TOCP (39 $\mu \mathrm{g} / \mathrm{g}$ ) were observed in heart tissue from rats given repeated oral doses $(50 \mathrm{mg} / \mathrm{kg}$ ) of this compound, suggesting that relatively high levels of metabolite are achievable. ${ }^{39}$ It may also be that longer exposure to PSP at lower concentrations can also induce caspase activation. In this respect, preliminary data (not shown) indicate that LDH release is significantly increased by exposure to $6 \mu \mathrm{M}$ PSP for 24-48 h.

\section{Identification of PSP binding proteins}

It is becoming increasing apparent that OPs interact with and/or modulate a number of molecular targets besides AChE. These include cytoskeletal proteins, proteolytic enzymes, mitochondrial enzymes, and signalling molecules. ${ }^{2,38}$ Furthermore, a prominent target for OPs that induce OPIDN, is neuropathy target esterase (NTE), a member of the patatin-like phospholipase (PNPLA) family whose functions include regulation of lipid metabolism and cell signalling. ${ }^{40-41}$ Although NTE (PNPLA6) has been detected in nonneuronal tissues including human heart, ${ }^{42}$ it is not known if mitotic or differentiated H9c2 cells express NTE. Although beyond the scope of the present study, it would be of interest to investigate NTE expression and the effect of PSP on NTE activity in H9c2 cells. In this study, we used fluorescently labelled PSP (dansylated PSP) in order to identify novel PSP binding proteins in $\mathrm{H} 9 \mathrm{c} 2$ cardiomyocytes. Mass spectrometry analysis identified tropomyosin, heat shock protein $\beta-1$ and nucleolar protein 58 as novel protein targets for PSP. Heat shock protein $\beta-1$ (also known as HSP-27) is a member of small heat shock protein family and is involved in the regulation of apoptosis, protection of cells against oxidative stress and modulation of the cytoskeleton. ${ }^{43-44}$ Hence it is plausible that PSP binding modulates the functioning of heat shock protein $\beta-1$ leading to induction of apoptosis. In skeletal and cardiac muscle tropomyosin regulates the interaction between actin and myosin, whereas in non-muscle cells it plays a role in regulating the actin cytoskeleton. ${ }^{45}$ Given the emerging role of the actin cytoskeleton as a regulator of apoptosis, ${ }^{46}$ it is conceivable that PSP binding to tropomyosin alters its 
interaction with other actin binding proteins (e.g. cofilin) that are linked to cytoskeleton mediated modulation of apoptotic signalling. ${ }^{46}$ Finally, PSP also bound to nucleolar protein 58 which is required for $60 \mathrm{~S}$ ribosomal subunit biogenesis. ${ }^{47}$ PSP binding to this protein might impair the translation of proteins essential for cell survival. It is important to note that the observed molecular weight $(\mathrm{kDa})$ and isoelectric point $(\mathrm{p} I)$ values for nucleolar protein 58 are lower than the expected values suggesting the identification of a proteolytic degradation product. Further work is therefore required in order to confirm the identity of nucleolar protein 58 as a PSP-binding protein. Overall, it remains to be established if there is a definitive link between any of these novel protein targets and PSP-induced cytotoxicity.

In summary, this study has investigated for the first time the effect of OPs on cardiomyocytes using differentiated H9c2 cells, a cell-based model system that displays a robust cardiomyocyte-like phenotype. The in vivo metabolites of OPs classified as potent AChE inhibitors (diazoxon and chlorpyrifos oxon) displayed no cytotoxicity towards mitotic or differentiated $\mathrm{H} 9 \mathrm{c} 2$ cells. In contrast, PSP, a weak AChE inhibitor, triggered cytotoxicity in differentiated H9c2 cardiomyoblasts via a pathway involving JNK1/2mediated activation of caspase-3. Furthermore, proteomic analysis using fluorescently labelled PSP identified tropomyosin, heat shock protein $\beta-1$ and nucleolar protein 58 as novel protein targets for PSP. Finally, whilst this study has focused on the effects and mechanisms of cytotoxic concentrations of PSP, on-going studies are exploring the effect(s) of sub-lethal concentrations of PSP on the differentiation of H9c2 cells and potential modulation of G-protein coupled receptor signalling pathways associated with cardiomyocytes.

\section{Funding}

This work was supported by a PhD studentship from the Saudi Arabian government (S10712). 


\section{ABBREVIATIONS}

AChE, acetylcholinesterase; BAS, bovine serum albumin; ERK1/2; extracellular signalregulated kinase $1 / 2 ; \mathrm{JNK} 1 / 2, \mathrm{c}$-Jun $\mathrm{N}$-terminal kinase $1 / 2 ; \mathrm{LDH}$, lactate dehydrogenase; MTT, 3-(4-5-dimethylthiazol-2-yl)-2,5-diphenyltetrazolium bromide; NTE, neuropathy target esterase; OP, organophosphorous compounds; OPIDN, OP-induced delayed neuropathy; PI-3K; phosphatidyl inositol 3-kinase; PKB, protein kinase B; p38 MAPK, p38 mitogen-activated protein kinase; PSP, phenyl saligenin phosphate; TBS, Trisbuffered saline; TOCP, tri-ortho-cresyl phosphate; 


\section{REFERENCES}

(1) Chambers, H. (1992) Organophosphate compounds: an overview. In

Organophosphates: chemistry, fate and effects. pp 3-17, Academic Press, New York.

(2) Hargreaves, A.J. (2012) Neurodegenerations induced by organophosphorus compounds. Adv. Exp. Med. Biol. 724, 189-204.

(3) Solbu, K., Daae, H.L., Thorud, S., Ellingsen, D.G., Lundanes, E., and Molander, P. (2010) Exposure to airborne organophosphates originating from hydraulic and turbine oils among aviation technicians and loaders. J. Environ. Monit. 12, 2259-2268.

(3) Solbu, K., Daae, H.L., Thorud, S., Ellingsen, D.G., Lundanes, E., and Molander, P. (2010) Exposure to airborne organophosphates originating from hydraulic and turbine oils among aviation technicians and loaders. J. Environ. Monit. 12, 2259-2268.

(4) Wecker, L., Mrak, R.E., and Dettbarn, W.D. (1986) Evidence of necrosis in human intercostal muscle following inhalation of an organophosphate insecticide. Fundam. Appl. Toxicol. 6, 172-174.

(5) Saadeh, A.M., Farsakh, N.A., and Al-Ali, M.K. (1997) Cardiac manifestations of acute carbamate and organophosphate poisoning. Heart 77, 461-464.

(6) Yavuz, T., Altuntas, I., Delibas, M., Yildirim, B., Candir, O., Cora, A., Karahan, N., Ibrisim, E., and Kutsal, A. (2004) Cardiotoxicity in rats induced by methidathion and ameliorating effects of vitamins E and C. Human Exp. Toxicol. 23, 323-329. 
(7) Abou Donia, M.B., and Lapadula, D.M. (1990) Mechanisms of organophosphorus ester induced delayed neurotoxicity: Type I and II. Ann. Rev. Pharmacol. Toxicol. 30, 405-440.

(8) Lotti, M. (1992) The pathogenesis of organophosphate polyneuropathy. Crit. Rev. Toxicol. 21, 465-487.

(9) Abou Donia, M.B. (2003) Organophosphorus ester induced chronic neurotoxicity. Arch. Env. Health 58, 484-497.

(10) El Fawal, H.A.N., Jortner, B.S., and Ehrich, M. (1989) Effect of verapamil on organophosphate-induced delayed neuropathy in hens. Toxicol. Appl. Pharmacol. 97, 500-511.

(11) El Fawal, H.A.N., Correl, L., Gay, L., and Ehrich, M. (1990) Protease activity in brain, nerve, and muscle of hens given neuropathy-inducing organophosphates and a calcium channel blocker. Toxicol. Appl. Pharmacol. 103, 133-142.

(12) Roth, A., Zellinger, I., Arad, M., and Atsmon, J. (1983) Organophosphates and the heart. Chest 103, 576-582.

(13) Ludomirsky, A., Klein, H., Sarelli, P., Becker, B., Hoffman, S., Taitelman, U., Barzilai, J., Lang, R., David, D., DiSegni, E., and Kaplinsky, E. (1982) Q-T prolongation and polymorphous (torsade de pointes) ventricular arrhythmias associated with organophosphorous insecticide poisoning. Am. J. Cardiol. 49, 1654-1658.

(14) Lzyhnikov, E.A., Savina, A.S., and Shepelev, V.M. (1975) Pathogenesis of disorders of cardiac rhythm and conductivity in acute organophosphate insecticide poisoning. Kardiologia 15, 126-129. 
(15) Karki, P., Ansari, J.A., Bhandary, S., and Koirala, S. (2004) Cardiac and electrocardiographical manifestations of acute organophosphate poisoning. Singapore Med. J. 45, 385-389.

(16) Anand, S., Singh, S., Nahar Saikia, U., Bhalla, A., Sharma, Y., and Singh, D. (2009) Cardiac abnormalities in acute organophosphate poisoning. Clin. Toxicol. 47, 230-235.

(17) Calore, E.E., Perez, N.M., and Hermann, M.M. (2007) Morphometric studies of cardiac myocytes from rats chronically treated with an organophosphate. Ecotoxicol. Environ. Saf. 66, 447-450.

(18) Ogutcu, A., Uzunhisarcikli, M., Kalender, S., Durak, D., Bayrakdar, F., and Kalender, Y. (2006) The effects of organophosphate insecticide diazinon on malondialdehyde levels and myocardial cells in rat heart tissue and protective role of vitamin E. Pestic. Biochem. Physiol 86, 93-98.

(19) Kimes, B.W., and Brandt, B.L. (1976) Properties of a clonal muscle cell line from rat heart. Exp. Cell Res. 98, 367-381.

(20) Hescheler, J., Meyer, R., Plant, S., Krautwurst, D., Rosenthal, W., and Schultz, G. (1991) Morphological, biochemical and electrophysiological characterization of a clonal cell (H9c2) line from rat heart. Circ. Res. 69, 1476-1486.

(21) Ménard, C., Pupier, S., Mornet, D., Kitzmann, M., Nargeot, J., and Lory, P. (1999) Modulation of L-type channel expression during retinoic acid-induced differentiation of H9c2 cardiac cells. J. Biol. Chem. 274, 29063-29070. 
(22) Comelli, M., Domenis, R., Bisetto, E., Contin, M., Marchini, M., Ortolani, F., Tomasetig, L., and Mavelli, I. (2011) Cardiac differentiation promotes mitochondria development and ameliorates oxidative capacity in H9c2 cardiomyoblasts. Mitochondrion $11,315-326$.

(23) Daubney, J., Bonner, P.L., Hargreaves, A.J., and Dickenson, J.M. (2014) Cardioprotective and cardiotoxic effects of quercetin and two of its in vivo metabolites on differentiated H9c2 cardiomyocytes. Basic Clin. Pharmacol. Toxicol. 116, 96-109.

(24) Ellman, G.L., Courtney, K.D., Andres ,V. Jnr, and Featherstone, R.M. (1961) A new and rapid colorimetric determination of acetylcholinesterase. Biochem. Pharmacol. 7, 8895.

(25) Flaskos, J., Harris, W., Sachana, M., Muñoz, D., Tack, J., and Hargreaves, A.J. (2007) The effects of diazinon and cypermethrin on the differentiation of neuronal and glial cell lines. Toxicol. Appl. Pharmacol. 219, 172-180.

(26) Armstrong, S.C. (2004) Protein kinase activation and myocardial ischaemia/reperfusion injury. Cardiovasc. Res. 61, 427-436.

(27) Hausenloy, D.J., and Yellon, D.M. (2007) Preconditioning and postconditioning: united at reperfusion. Pharmacol. Ther. 114, 208-221.

(28) Bennett, B.L., Sasaki, D.T., Murray, B.W., O'Leary, E.C., Sakata, S.T., Xu, W., Leisten J.C., Motiwala, A., Pierce, S., Satoh, Y., Bhagwat, S.S., Manning, A.M., and Anderson D.W. (2001) SP 600125, an anthrapyrazolone inhibitor of Jun N-terminal kinase. Proc. Natl. Acad. Sci. 98, 13681-13686. 
(29) Jortner, B.S., and Ehrich, M. (1987) Neuropathological effects of phenyl saligenin phosphate in chickens. Neurotoxicol. 8, 303-314.

(30) Slavíková, J., Vlk, J., and Hlavicková, V. (1982) Acetylcholinesterase and butyrylcholinesterase activity in the atria of the heart of adult albino rats. Physiol. Bohemoslov. 31, 407-414.

(31) Marsillach, J., Richter, R.J., Kim, J.H., Stevens, R.C., MacCoss, M.J., Tomazela, D., Suzuki, S.M., Schopfer, L.M., Lockridge, O., and Furlong, C.E. (2011) Biomarkers of organophosphorous (OP) exposures in humans. Neurotoxicol.32, 656-660

(32) Sax, N.I., and Lewis, R.J. Sr (1987) Hawley's Condensed Chemical Dictionary 11th edn. p1178, Van Nostrand Reinhold Co, New York.

(33) Winder, C. (2006) Air monitoring studies for air cabin contamination. Curr. Top. Toxicol. 3, 33-48.

(34) Fotakis, G., and Timbrell, J.A. (2006) In vitro cytotoxic assays: comparison of LDH, neutral red, MTT and protein assay in hepatoma cells following exposure to cadmium chloride. Toxicol. Lett. 160, 171-77.

(35) Harris, W., Muñoz, D., Bonner, P.L.R., and Hargreaves, A.J. (2009) Effects of phenyl saligenin phosphate on cell viability and transglutaminase activity in N2a neuroblastoma and HepG2 hepatoma cells. Toxicol. In Vitro 23, 1559-1563.

(36) Carlson, K., Jortner, B.S., and Ehrich, M. (2000) Organophosphorus compoundinduced apoptosis in SH-SY5Y human neuroblastoma cells. Toxicol. Appl. Pharmacol. $168,102-113$. 
(37) Hargreaves, A.J., Fowler, M.J., Sachana, M., Flaskos, J., Bountouri, M., Coutts, I.C., Glynn, P., Harris, W., and McLean, W.G. (2006) Inhibition of neurite outgrowth in differentiating mouse N2a neuroblastoma cells by phenyl saligenin phosphate: Effects on MAP kinase (ERK1/2) activation, neurofilament heavy chain phosphorylation and neuropathy esterase activity. Biochem. Pharmacol. 71, 1240-1247.

(38) Pomeroy-Black, M., and Ehrich, M. (2012) Organophosphorus compound effects on neurotrophin receptors and intracellular signalling. Toxicol. In Vitro 26, 759-765.

(39) Somkuti, S.G., and Abou-Donia, M.B. (1990) Disposition, elimination, and metabolism of tri-o-cresyl phosphate following daily oral administration in Fischer 344 male rats. Arch. Toxicol.64, 572-579.

(40) Chang, P.A., and Wu, Y.J. (2010) Neuropathy target esterase: an essential enzyme for neural development and axonal development. Int. J. Biochem. Cell Biol. 42, 573-575.

(41) Richardson, R.J., Hein, N.D., Wijeyesakere, S.J., Fink, J.K., and Makhaeva, G.F. (2013) Neuropathy target esterase (NTE): overview and future. Chem.-Biol. Interact. $203,238-244$.

(42) Wilson, P.A., Gardner, S.D., Lambie, N.M., Commans, S.A., and Crowther, D.J. (2006) Characterization of the human patatin-like phospholipase family. J. Lipid Res. 47, 1940-1949.

(43) Mymrikov, E.V., Seit-Nebi, A.S., and Gusev, N.B. (2011) Large potentials of small heat shock proteins. Physiol. Rev. 91, 1123-1159. 
(44) Wettstein, G., Bellaye, P.S., Michaeu, O., and Bonniaud, P. (2012) Small heat shock proteins and the cytoskeleton. An essential interplay for cell integrity? Int. J. Biochem. Cell Biol. 44, 1680-1686.

(45) Gunning, P., O’Neill, G., and Hardeman, E. (2008) Tropomyosin-based regulation of the actin-cytoskeleton in time and space. Physiol. Rev. 88, 1-35.

(46) Desouza, M., Gunning, P.W., and Stehn, J.R. (2012) The actin cytoskeleton as a sensor and mediator of apoptosis. Bioarchitecture 2, 75-87.

(47) Lyman, S.K., Gerace, L., and Baserga, S.J. (1999) Human Nop5/Nop58 is a component common to the box C/D small nucleolar ribonucleoproteins. RNA 5, 15971604. 


\section{FIGURE LEGENDS}

Figure 1. Chemical structures of A) phenyl saligenin phosphate (PSP) and B) dansylated PSP.

Figure 2. Effect of chlorpyrifos on the viability of mitotic H9c2 cells monitored by MTT reduction. Mitotic $\mathrm{H} 9 \mathrm{c} 2$ cells were exposed to the indicated concentrations of chlorpyrifos for A) $24 \mathrm{~h}$ and B) $48 \mathrm{~h}$. Following chlorpyrifos exposure cell viability was assessed by measuring the metabolic reduction of MTT by cellular dehydrogenases. Data are expressed as the percentage of control cells $(=100 \%)$ and represent the mean \pm SEM of four independent experiments each performed in quadruplicate. $* * * * p<0.0001$ versus control response.

Figure 3. Effect of phenyl saligenin phosphate (PSP) on the viability of mitotic H9c2 cells monitored by MTT reduction and LDH release. Mitotic H9c2 cells were exposed to the indicated concentrations of PSP for $4 \mathrm{~h}$ (panels A and B) $8 \mathrm{~h}$ (panels $\mathrm{C}$ and D). Following PSP exposure cell viability was assessed by measuring the metabolic reduction of MTT by cellular dehydrogenases ( $A$ and $C$ ) and release of LDH ( $B$ and $D$ ). Data are expressed as the percentage of control cells $(=100 \%)$ and represent the mean \pm SEM of three independent experiments each performed in quadruplicate (MTT) or sextuplicate (LDH). $* p<0.05, * * p<0.01, * * * p<0.001$ and $* * * * p<0.0001$ versus control response.

Figure 4. Effect of chlorpyrifos on the viability of differentiated H9c2 cells monitored by MTT reduction and LDH release. Differentiated H9c2 cells (7 day) were exposed to the indicated concentrations of chlorpyrifos for $24 \mathrm{~h}$ (panels A and B) $48 \mathrm{~h}$ (panels C and D). Following chlorpyrifos exposure cell viability was assessed by measuring the metabolic reduction of MTT by cellular dehydrogenases ( $A$ and $C$ ) and release of $L D H(B$ and $D)$. Data are expressed as the percentage of control cells $(=100 \%)$ and represent the mean \pm SEM of three independent experiments each performed in quadruplicate (MTT) or 
sextuplicate (LDH). ${ }^{*} p<0.05, * * p<0.01, * * * p<0.001$ and $* * * * p<0.0001$ versus control response.

Figure 5. Effect of phenyl saligenin phosphate (PSP) on the viability of differentiated H9c2 cells monitored by MTT reduction and LDH release. Differentiated H9c2 cells (7 day) were exposed to the indicated concentrations of PSP for $2 \mathrm{~h}$ (panel A), $4 \mathrm{~h}$ (panels $\mathrm{B}$ and D) $8 \mathrm{~h}$ (panels $\mathrm{C}$ and E). Following PSP exposure cell viability was assessed by measuring the metabolic reduction of MTT by cellular dehydrogenases $(A, B, C)$ and release of $\operatorname{LDH}(\mathrm{D}, \mathrm{E})$. Data are expressed as the percentage of control cells $(=100 \%)$ and represent the mean \pm SEM of at least three independent experiments each performed in quadruplicate (MTT) or sextuplicate (LDH). ${ }^{*} p<0.05, * * \quad p<0.01$, $* * * p<0.001$ and $* * * * p<0.0001$ versus control response.

Figure 6. PSP-induced caspase-3 activation in differentiated H9c2 cells. Differentiated H9c2 cells (7 day) were incubated without (-) or with (+) $25 \mu \mathrm{M}$ PSP for the indicated time periods. Following PSP exposure caspase-3 activation was assessed via A) Western blotting using anti-active caspase 3 antibody or B) via immunocytochemistry using antiactive caspase 3 antibody (green) and DAPI counterstain for nuclei visualisation (blue). Images presented are from one experiment and representative of three. In (A) data are expressed as the percentage of reactivity control cell lysates and represent the mean \pm SEM of three independent experiments. ${ }^{*} p<0.05$ versus time matched control cells.

Figure 7. Effects of PSP on acetylcholinesterase activity. Cells were induced to differentiate for 7 days and then exposed to PSP $(8 \mathrm{~h}, 25 \mu \mathrm{M})$. Shown are the mean specific activities \pm SEM from three independent experiments. Asterisk indicates a significant difference from the non PSP treated control (Student's T test; $p<0.05$ ). 
Figure 8. PSP-induced JNK1/2 activation in differentiated H9c2 cells. Differentiated H9c2 cells ( 7 days) were exposed to $25 \mu \mathrm{M}$ PSP for the indicated time periods. Following PSP exposure JNK1/2 activation was assessed via Western blotting using a phospho-specific JNK1/2 antibody. Samples were subsequently analysed on separate blots using an antibody that recognises total JNK1/2. Quantified data are expressed as the ratio of phosphorylated JNK1/2 to total JNK1/2 and represent the mean \pm SEM of four independent experiments. $* * * * p<0.0001$ versus control cells.

Figure 9. Effect of the JNK1/2 inhibitor SP 600125 on PSP-induced inhibition of MTT reduction and release of $\mathrm{LDH}$. Differentiated H9c2 cells (7 days) were exposed to $25 \mu \mathrm{M}$ PSP for $4 \mathrm{~h}$ (panels $\mathrm{A}$ and $\mathrm{B}$ ) and $8 \mathrm{~h}$ (panels $\mathrm{C}$ and $\mathrm{D}$ ) in the presence and absence of SP 600125 as indicated. Following PSP exposure cell viability was assessed by measuring the metabolic reduction of MTT by mitochondrial dehydrogenases ( $B$ and $D$ ) and release of $\operatorname{LDH}(\mathrm{A}$ and $\mathrm{C})$. Data are expressed as the percentage of control cells $(=100 \%)$ and represent the mean \pm SEM of at least three independent experiments each performed in quadruplicate (MTT) or sextuplicate (LDH). ${ }^{*} p<0.05, * * p<0.01, * * * p<0.001$ and $* * * * p<0.0001$ versus control response.

Figure 10. Effect of the JNK1/2 inhibitor SP 600125 on PSP-induced JNK1/2 activation. Differentiated H9c2 cells ( 7 day) were exposed to $25 \mu \mathrm{M}$ PSP for A) $1 \mathrm{~h}, \mathrm{~B}$ ) $2 \mathrm{~h}$, and C) 4 $\mathrm{h}$ in the presence and absence of SP 600125 (10 $\mu \mathrm{M} ; 30$ min pre-incubation). Following PSP exposure JNK1/2 activation was assessed via Western blotting using a phosphospecific JNK1/2 antibody. Samples were subsequently analysed on a separate blot using an antibody that recognises total JNK1/2. Data are expressed as the percentage of control cells $(100 \%)$ and represent the mean \pm SEM of three independent experiments. $* p<0.05$ versus untreated control cells.

Figure 11. Effect of the JNK1/2 inhibitor SP 600125 on PSP-induced caspase 3 activation. Differentiated H9c2 cells ( 7 day) were exposed to $25 \mu \mathrm{M}$ PSP for A) $1 \mathrm{~h}, \mathrm{~B}$ ) $2 \mathrm{~h}$, and C) 4 
$\mathrm{h}$ in the presence and absence of SP 600125 (10 $\mu \mathrm{M} ; 30$ min pre-incubation). Following PSP exposure caspase 3 activation was assessed via immunocytochemistry using active caspase 3 antibody (green) and DAPI counterstain for nuclei visualisation (blue). Scale bar $=100 \mu \mathrm{m}$. Images presented are from one experiment and representative of four. Quantified data are expressed as the percentage of control cells and represent the mean \pm SEM of four independent experiments. $* * p<0.01, * * * p<0.001$ and $* * * * p<0.0001, a)$ versus control and $b$ ) versus PSP alone treated cells.

Figure 12. Effect of dansylated PSP on the viability of differentiated H9c2 cells monitored by $\mathrm{MTT}$ reduction and $\mathrm{LDH}$ release. Differentiated $\mathrm{H} 9 \mathrm{c} 2$ cells (7 day) were exposed to the indicated concentrations of dansylated PSP for $8 \mathrm{~h}$. Following PSP exposure cell viability was assessed by measuring the metabolic reduction of MTT by mitochondrial dehydrogenases $(A)$ and the release of LDH (B). Data are expressed as the percentage of control cells $(=100 \%)$ and represent the mean \pm SEM of three (MTT) or four (LDH) independent experiments each performed in quadruplicate (MTT) or sextuplicate (LDH). $* p<0.05, * * p<0.01, * * * p<0.001$ and $* * * * p<0.0001$ versus control response.

Figure 13. Visualisation of proteins labelled with dansylated PSP. Differentiated H9c2 cells were untreated or treated with dansylated PSP $(8 h, 25 \mu M)$ and cell lysates processed and analysed by 2D gel electrophoresis using $\mathrm{pH}$ 3-10 gradient strips. Gels were visualised under UV light (panels $A$ and $B$ ) prior to staining with ProtoBlue ${ }^{\mathrm{TM}}$ safe colloidal Coomassie G-250 stain (panels C and D). Gel images were analysed using Progenesis SameSpots software and circled spots represent those labelled with dansylated PSP. Spot 1: nucleolar protein 58; Spot 2: tropomyosin $\alpha-4$; Spot 3: heat shock protein $\beta-1$. A list of identified proteins labelled by dansylated PSP is provided in Table 1. 
Figure 14. Labelling of purified human heart tropomyosin with dansylated PSP. Human heart tropomyosin $(10 \mu \mathrm{g})$ was incubated for $1 \mathrm{~h}$ in presence or absence of dansylated/unlabelled PSP $(25 \mu \mathrm{M})$. Tropomyosin samples were then subjected to $10 \%$ $(w / v)$ polyacrylamide gel electrophoresis and subsequently stained with coomassie blue (A) and visualised under UV light (B). Lane 1: tropomyosin incubated with Tris-buffered saline; Lane 2: tropomyosin incubated with DMSO; Lane 3: tropomyosin incubated with PSP; Lane 4: tropomyosin incubated with dansylated PSP. 
Table 1. Identification of PSP-binding proteins in differentiated H9c2 cells. H9c2 cells treated with dansylated PSP $(1 \mathrm{~h}, 25 \mu \mathrm{M})$ were analysed by 2D gel electrophoresis and PSP-labelled proteins identified using MALDI-TOF MS ${ }^{a}$ (PMF) or MS/MS ${ }^{b}$ as described in Materials and Methods. Sequence data was analysed using MASCOT software and reported according to percentage sequence coverage (SC\%) or mascot score (ion scores for MS/MS > 27 indicate identity or extensive homology; >51 for PMF). All identified proteins exhibited MASCOT scores which were considered statistically significant $(p<0.05)$.

\begin{tabular}{llllllll}
\hline $\begin{array}{l}\text { Spot } \\
\text { number }\end{array}$ & Protein & $\begin{array}{l}\text { Accession } \\
\text { no. }\end{array}$ & $\begin{array}{l}\text { PMF } \\
\text { Sequence } \\
\text { Coverage } \\
(\%)^{\mathbf{a}}\end{array}$ & $\begin{array}{l}\text { Identified } \\
\text { Peptide } \\
\text { sequence } \\
\text { (MS/MS) }\end{array}$ & $\begin{array}{l}\text { Mascot } \\
\text { score }^{\mathbf{b}}\end{array}$ & kDa & pI \\
\hline 2 & Tropomyosin $\alpha-4$ & P09495 & 39 & & $52 / 51$ & 28.5 & 4.4 \\
3 & $\begin{array}{l}\text { Heat shock } \\
\text { protein } \beta-1 \\
\text { (HSP-27) }\end{array}$ & P42930 & & LFDQAFGVPR & $80 / 27$ & 22.9 & 6.1 \\
& $\begin{array}{l}\text { Nucleolar protein } \\
58\end{array}$ & Q9Q286 & 32 & & & & \\
1 & & & & $52 / 51$ & 59.5 & 9.2 \\
\hline
\end{tabular}


Figure 1

a)<smiles>O=P1(Oc2ccccc2)OCc2ccccc2O1</smiles>

Phenyl saligenin phosphate, PSP

b)<smiles>CN(C)c1cccc2c(S(=O)(=O)NCCCCCCOP3(=O)OCc4ccccc4O3)cccc12</smiles> 
Figure 2.
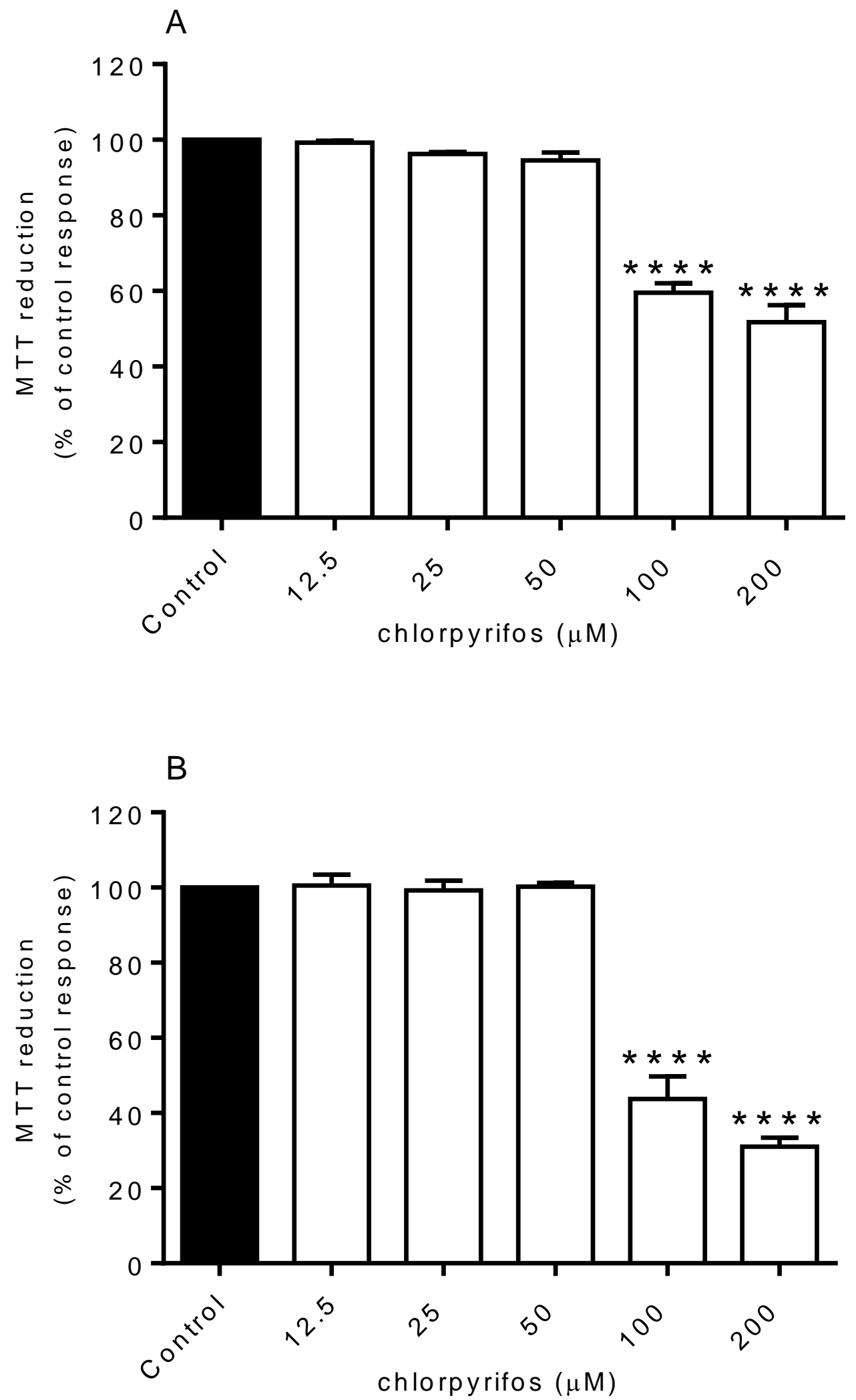
Figure 3.
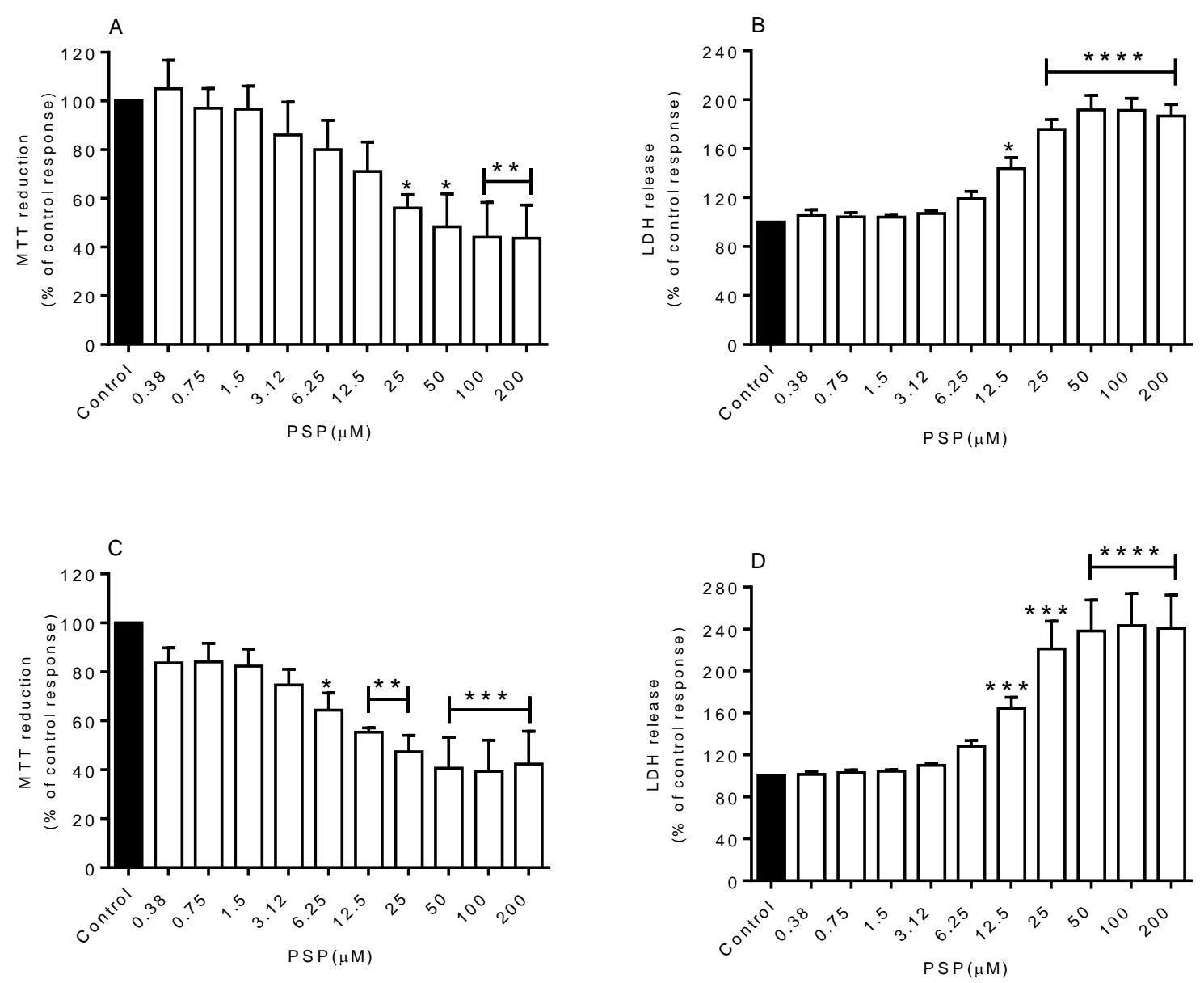
Figure 4.
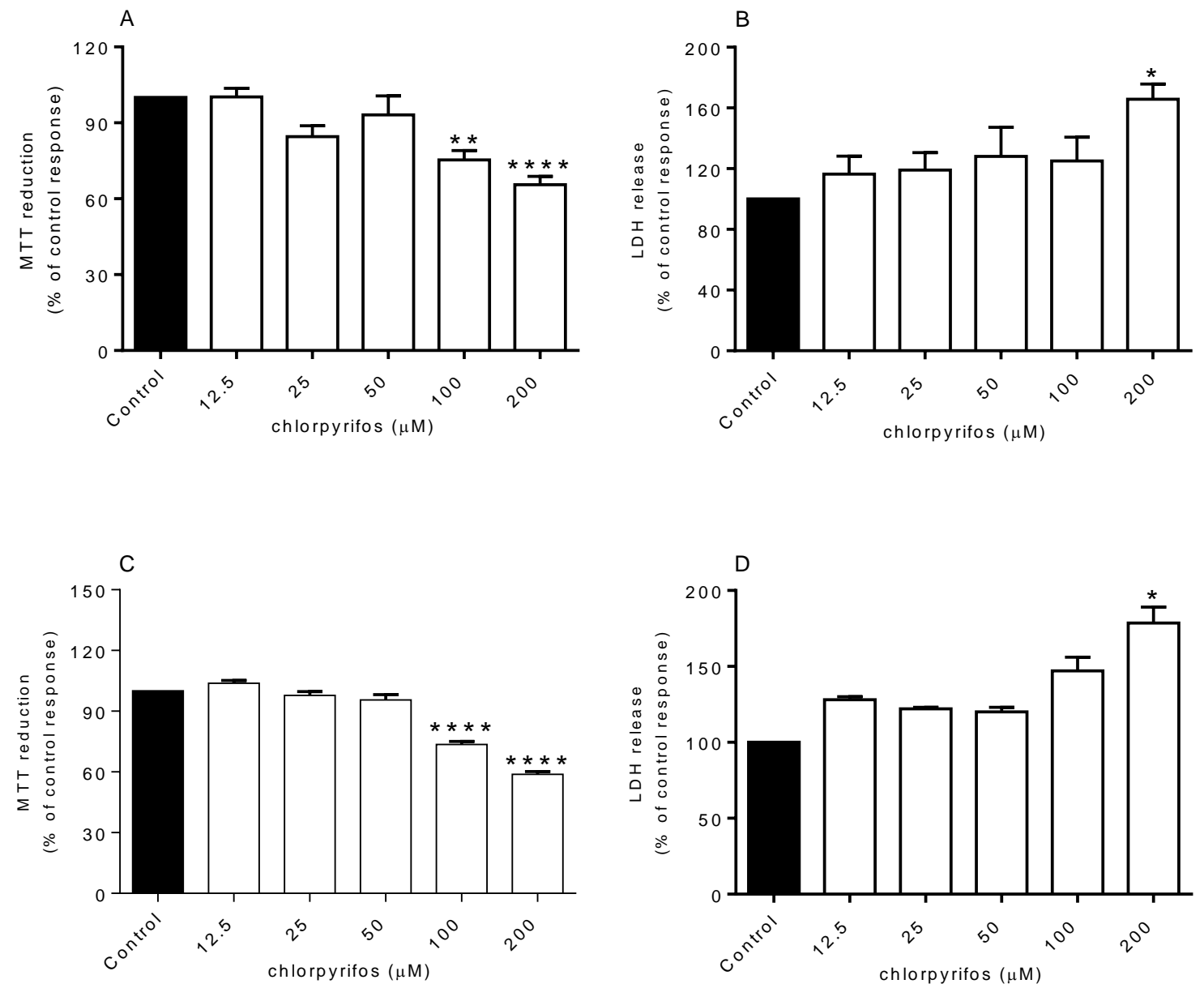
Figure 5.
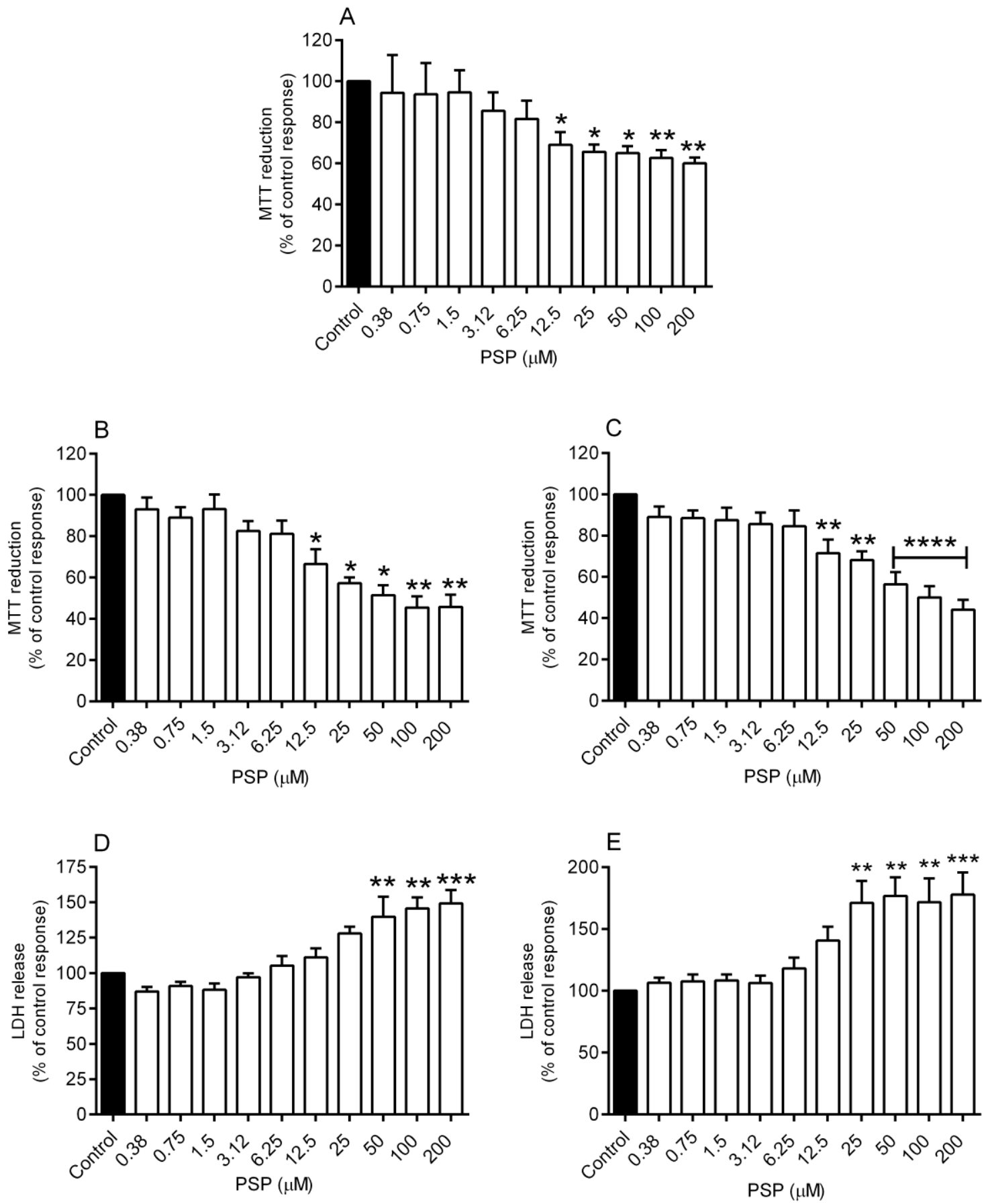
Figure 6.

A. control $\frac{1 \mathrm{~h}}{-} \quad \frac{2 \mathrm{~h}}{-} \quad \frac{4 \mathrm{~h}}{+} \quad \frac{8 \mathrm{~h}}{-+}$
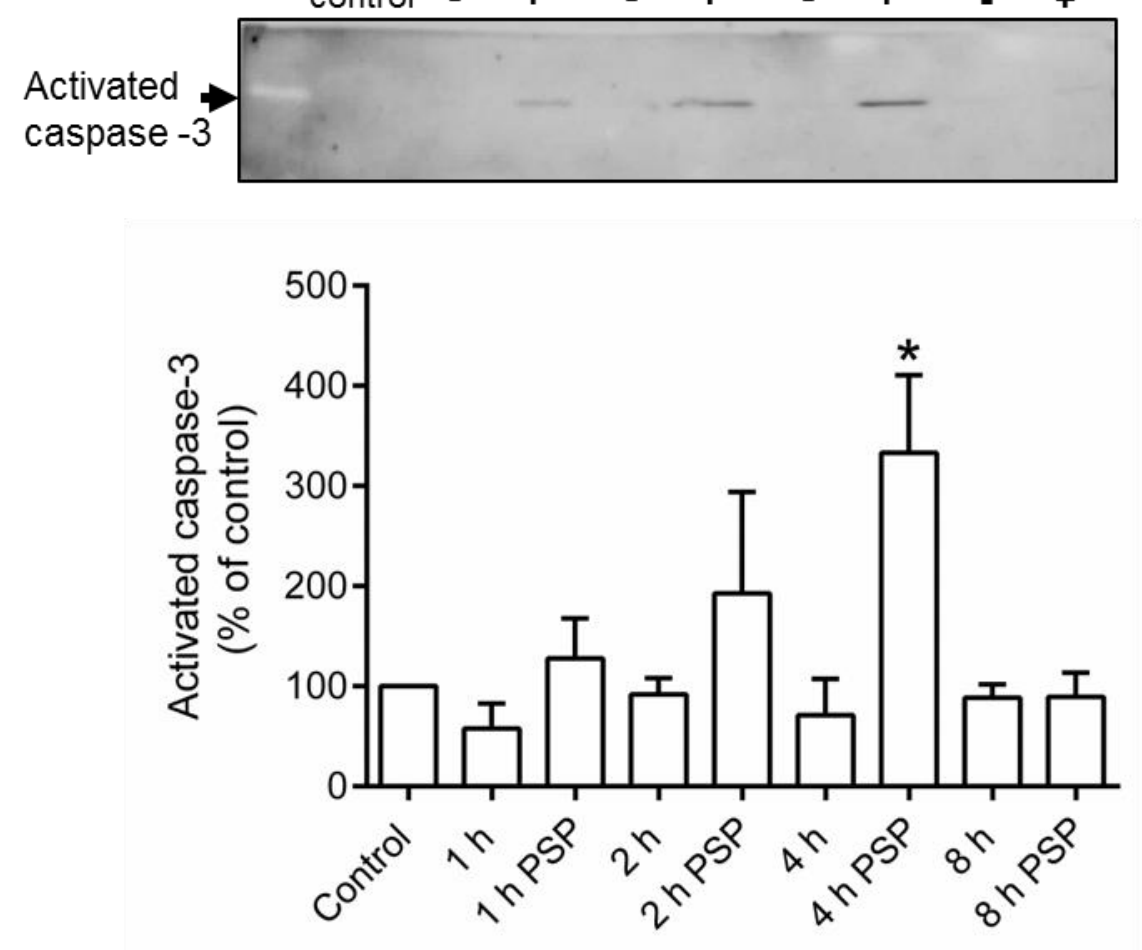

B.

control

PSP $(25 \mu \mathrm{M})$
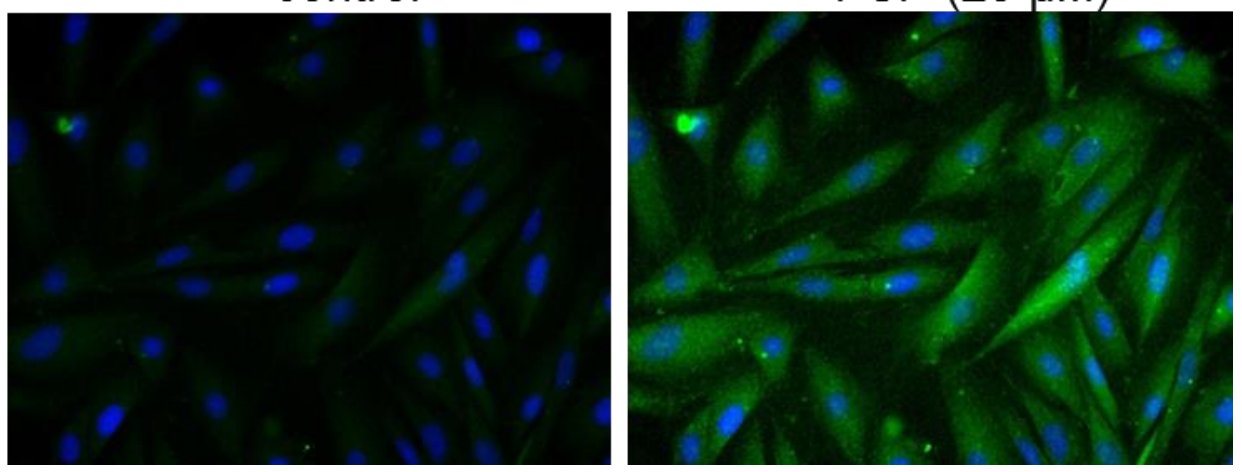
Figure 7.

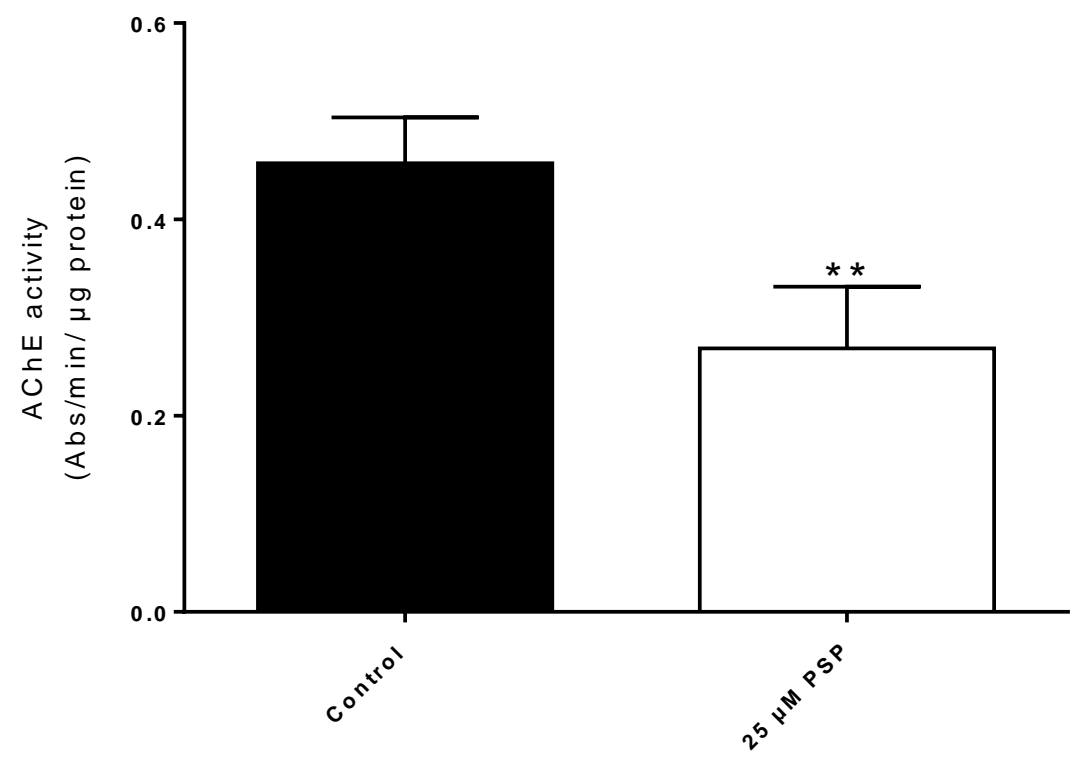


Figure 8.
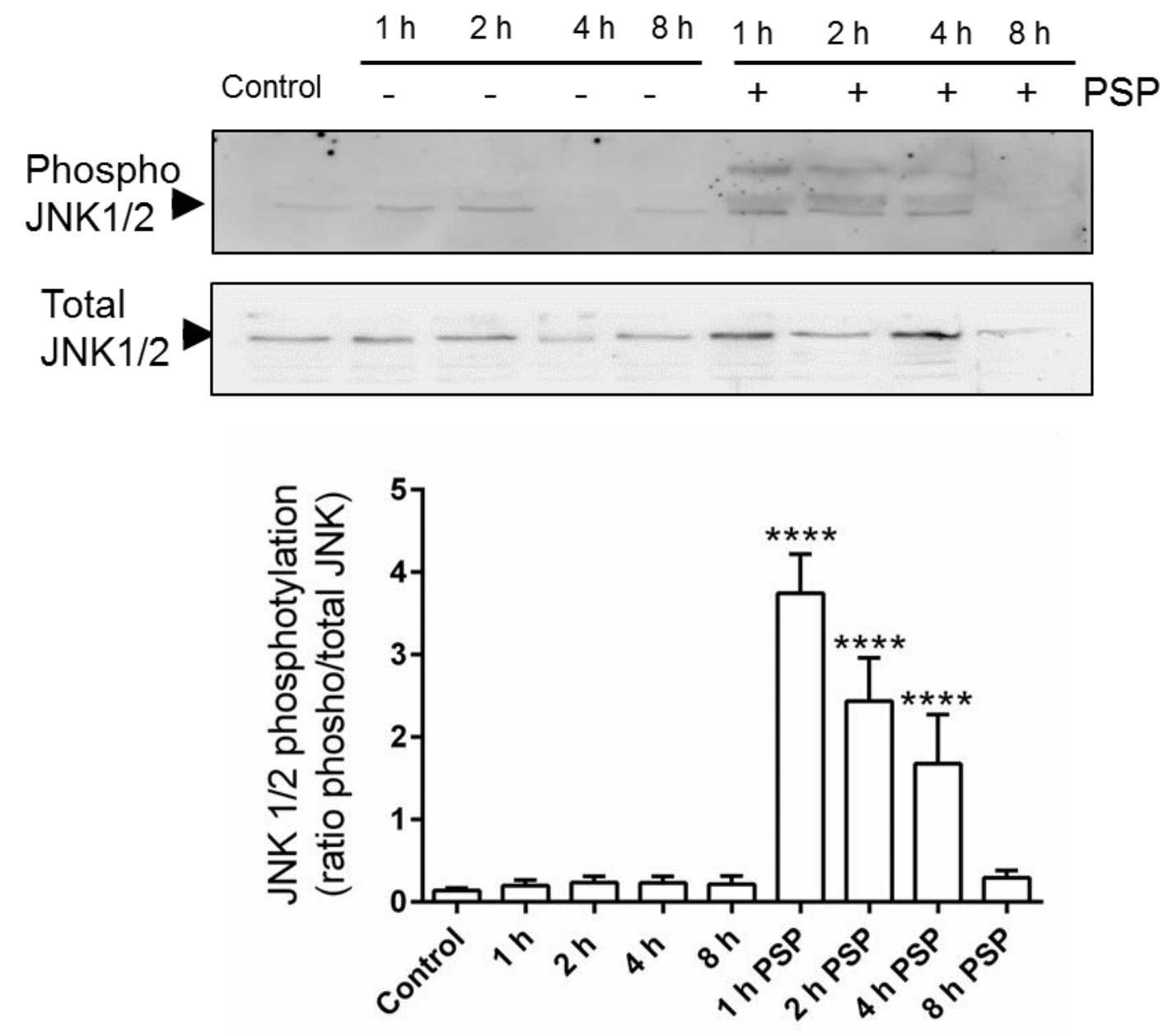
Figure 9.
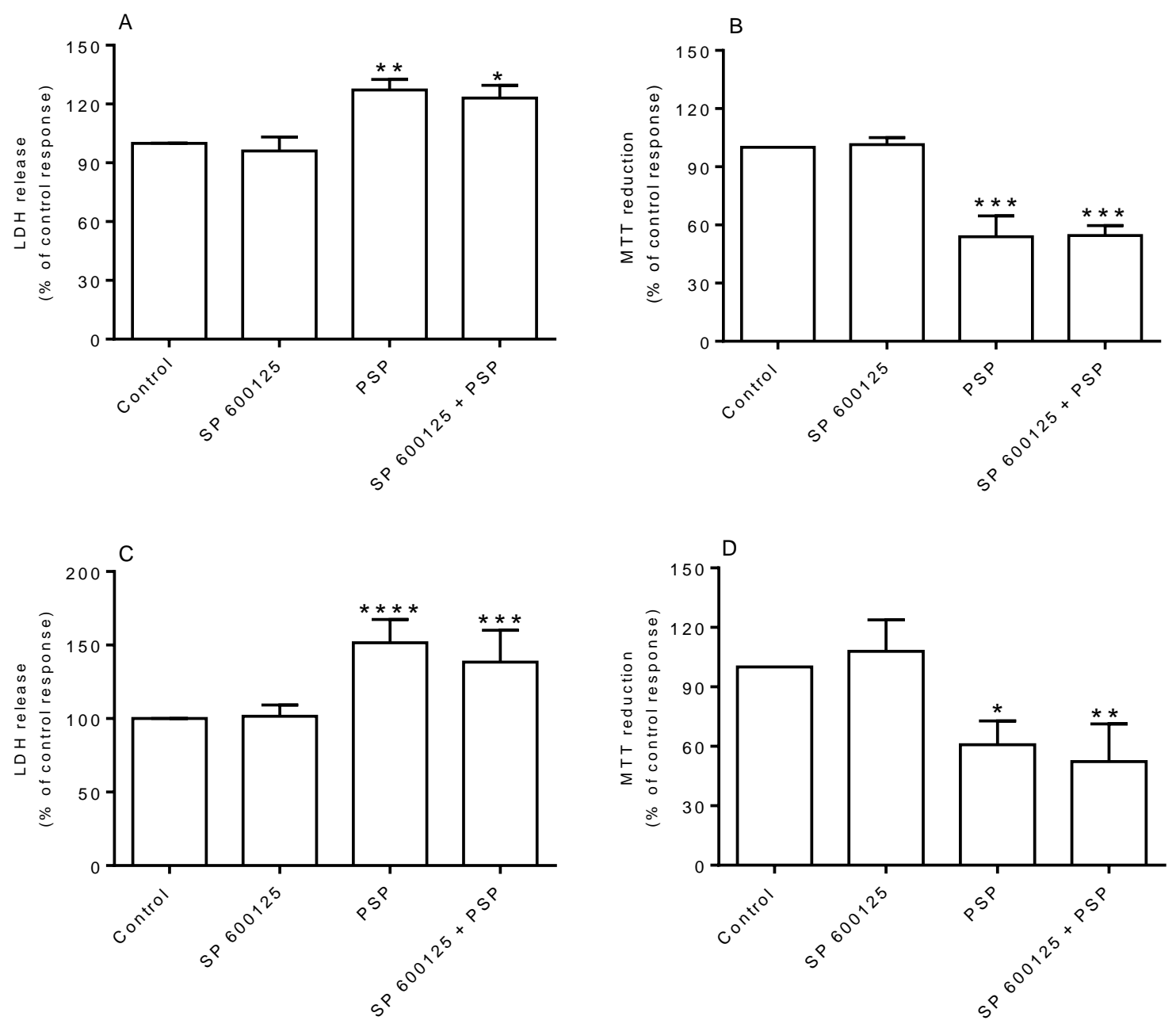
Figure 10.

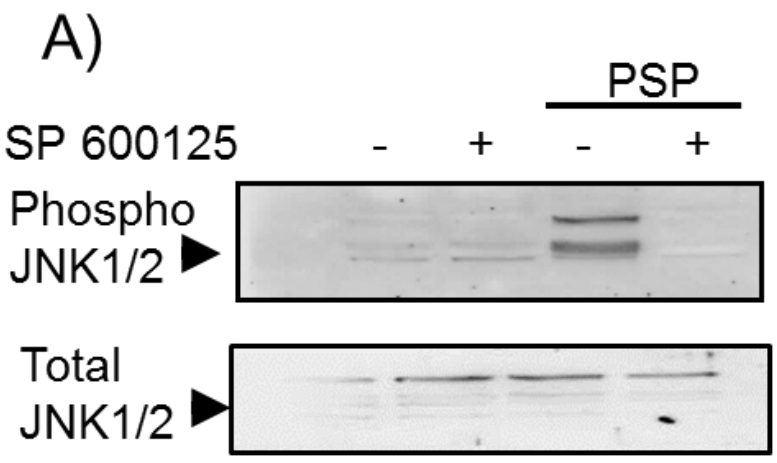

B)
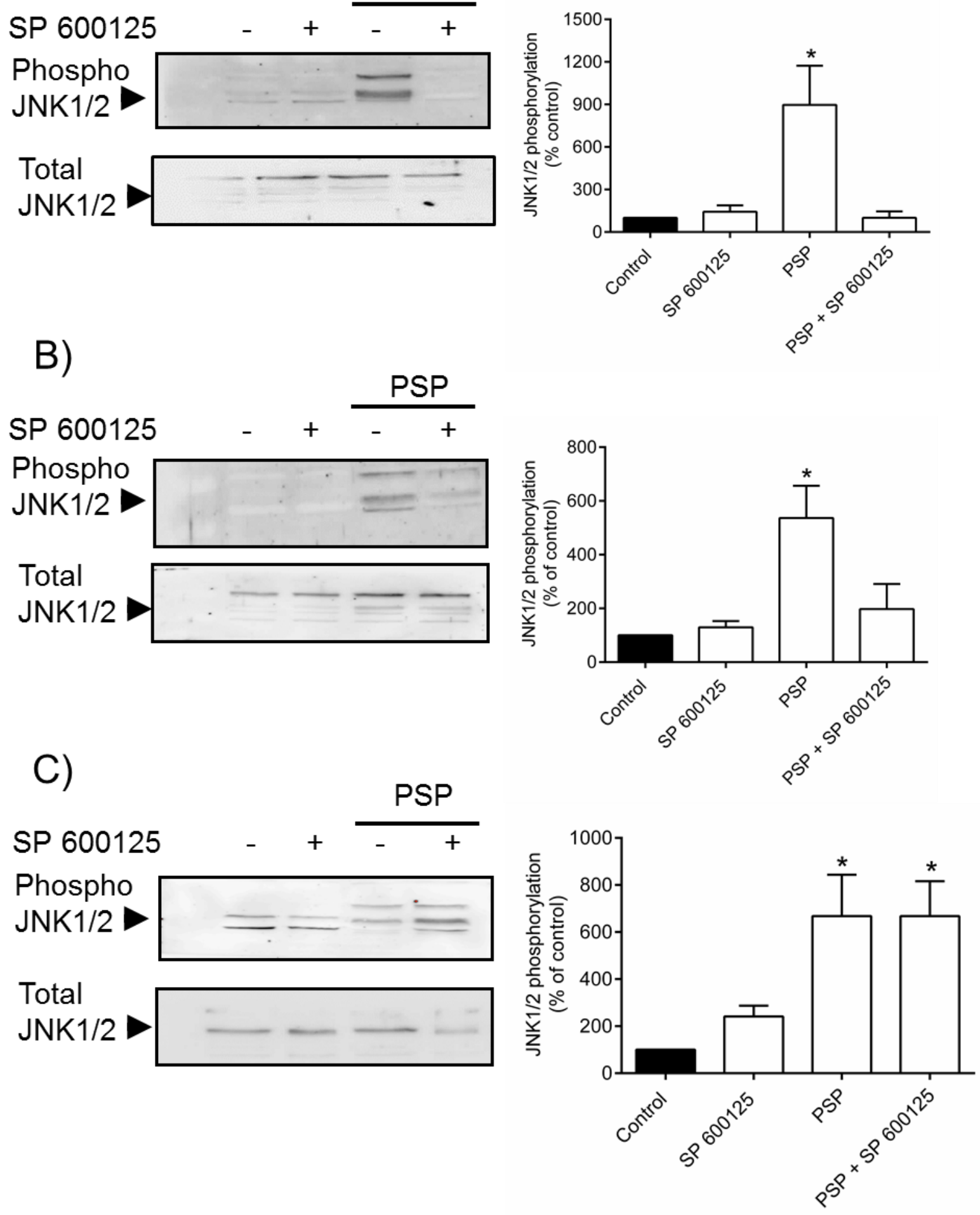
Figure 11.

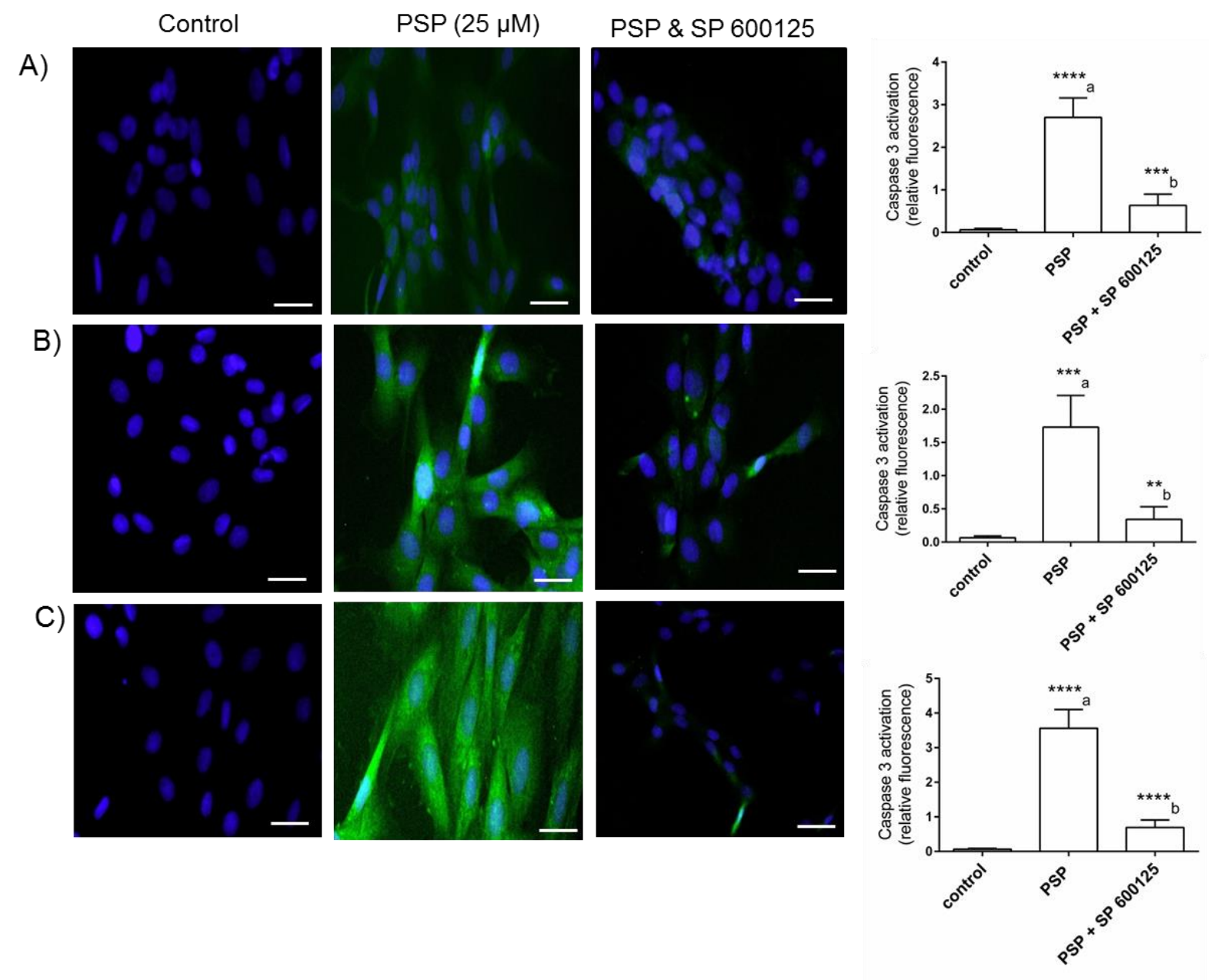


Figure 12.
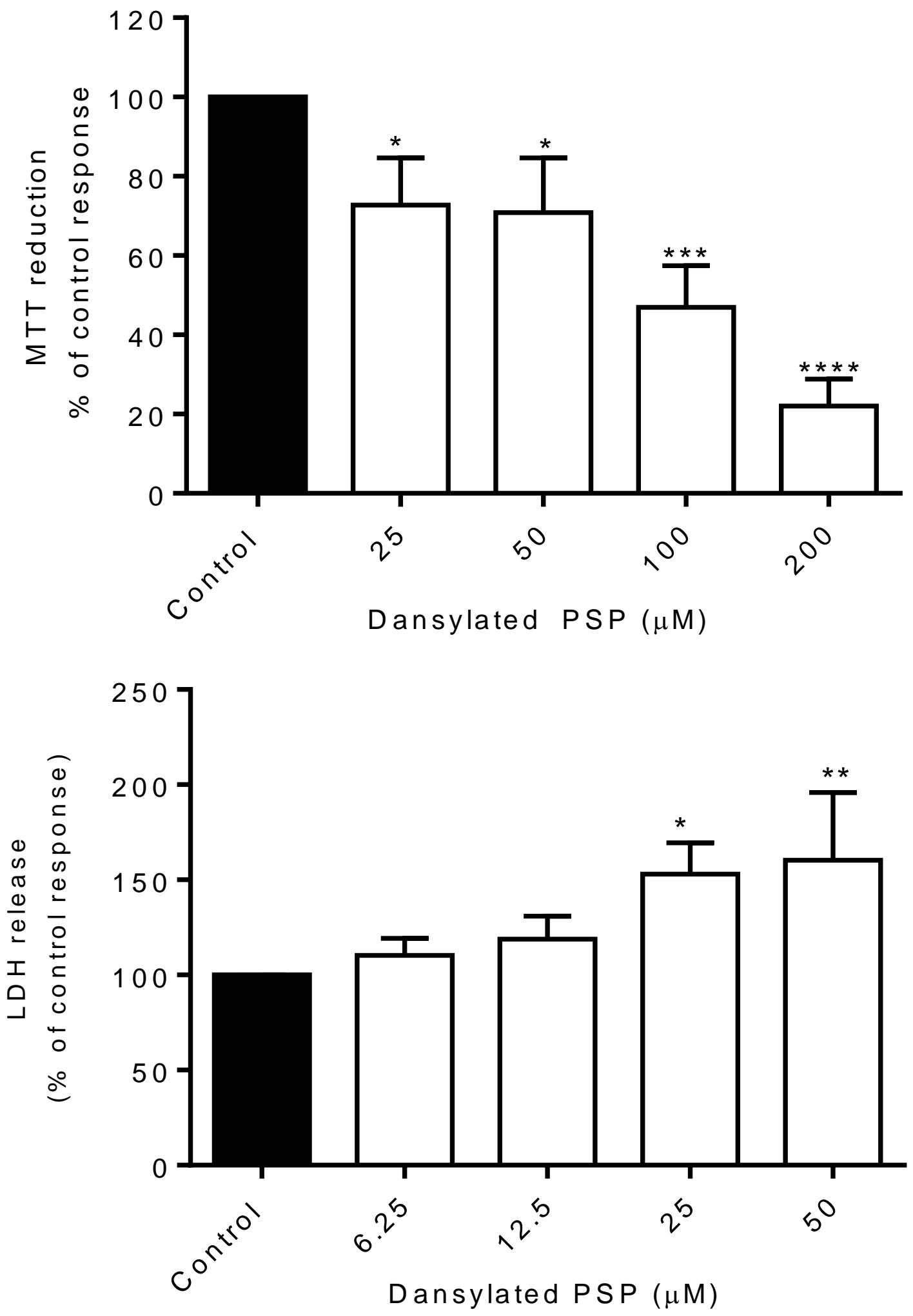
Figure 13.

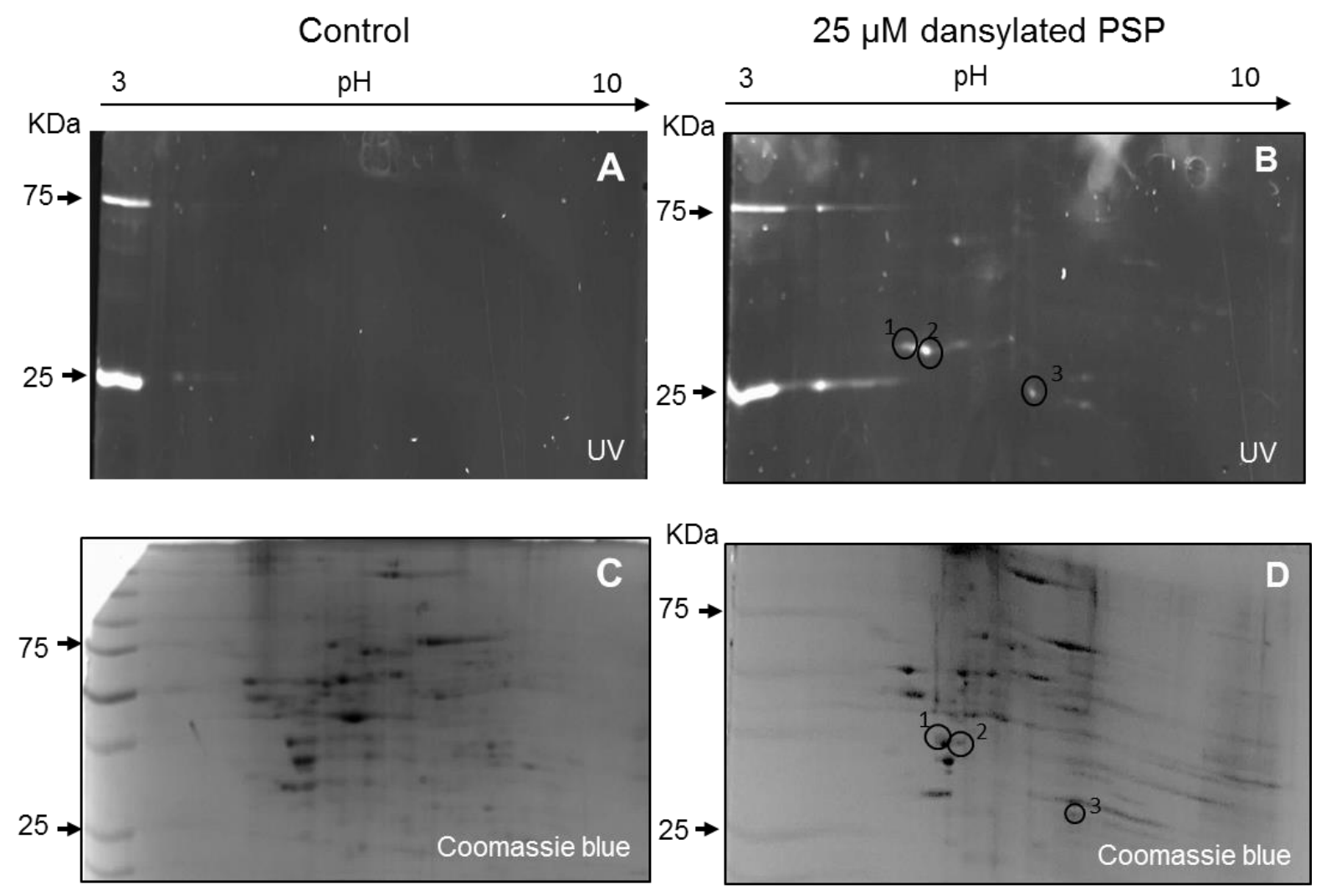


Figure 14.

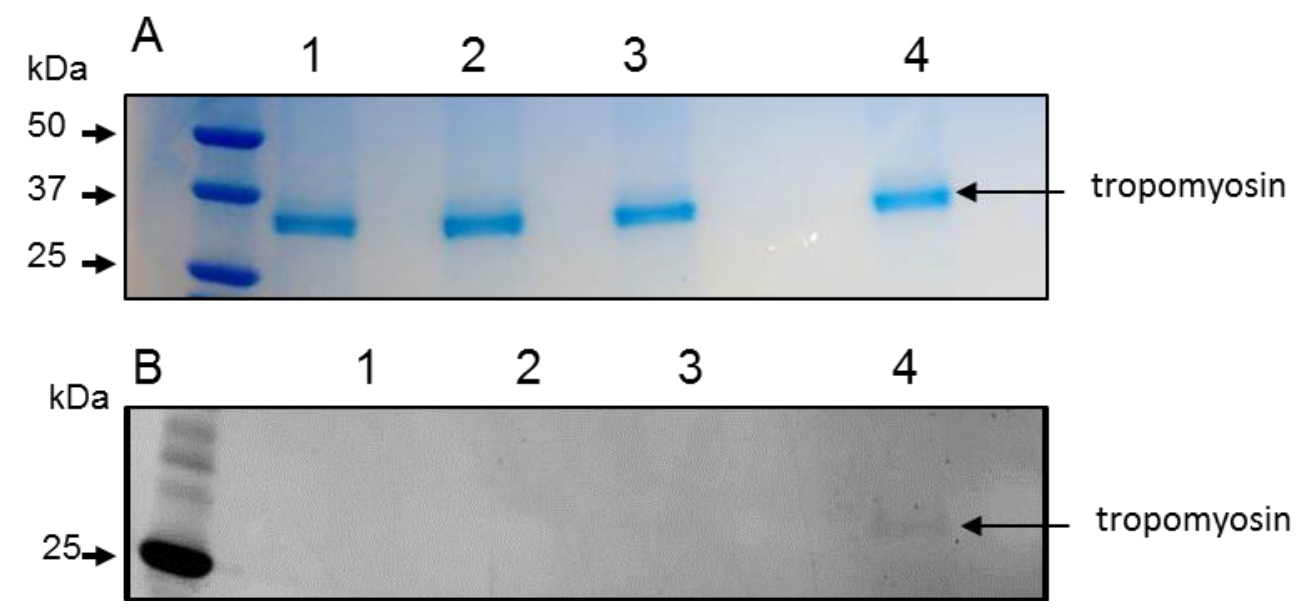




\section{Supplementary data}

Figure 1 Effect of phenyl saligenin phosphate (PSP) on the viability of mitotic H9c2 cells monitored by MTT reduction and LDH release. Mitotic H9c2 cells were exposed to the indicated concentrations of PSP for $4 \mathrm{~h}$ (panels $A$ and B) $8 \mathrm{~h}$ (panels $\mathrm{C}$ and D). Following PSP exposure cell viability was assessed by measuring the metabolic reduction of MTT by cellular dehydrogenases ( $A$ and $C$ ) and release of $\mathrm{LDH}$ ( $B$ and $D$ ). Organophosphate concentration response curves were obtained by computer assisted curve fitting using Prism software as described in Materials and Methods. Data are expressed as the percentage of control cells $(=100 \% ; \square)$ and represent the mean \pm SEM of three independent experiments each performed in quadruplicate (MTT) or sextuplicate (LDH). $* p<0.05, * * p<0.01, * * * p<0.001$ and $* * * * p<0.0001$ versus control response.
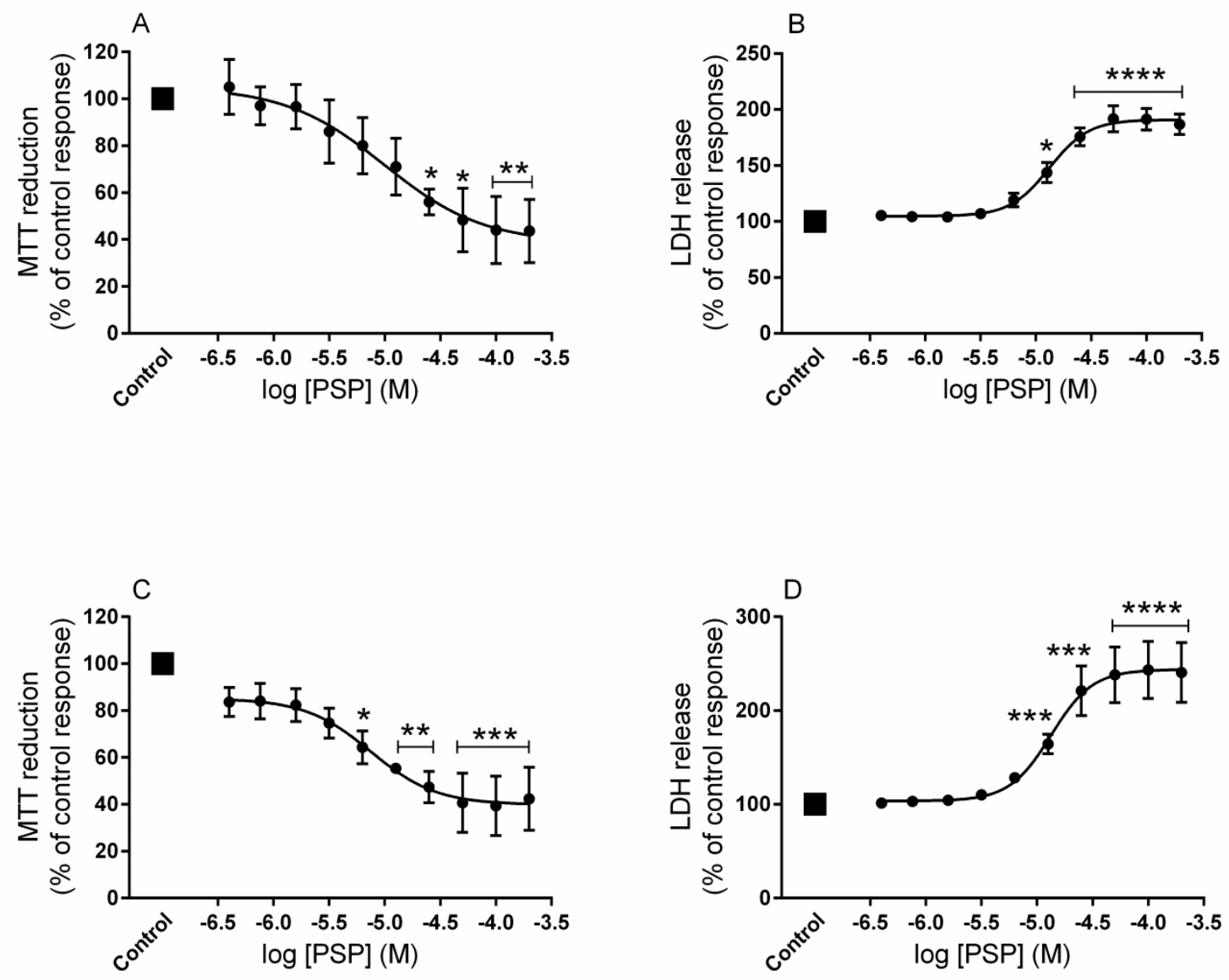
Figure 2. Effect of phenyl saligenin phosphate (PSP) on the viability of differentiated H9c2 cells monitored by MTT reduction and LDH release. Differentiated H9c2 cells (7 day) were exposed to the indicated concentrations of PSP for $2 \mathrm{~h}$ (panel A), $4 \mathrm{~h}$ (panels $B$ and D) $8 \mathrm{~h}$ (panels $C$ and E). Following PSP exposure cell viability was assessed by measuring the metabolic reduction of MTT by cellular dehydrogenases $(A, B, C)$ and release of $L D H(D, E)$. Organophosphate concentration response curves were obtained by computer assisted curve fitting using Prism software as described in Materials and Methods Data are expressed as the percentage of control cells $(=100 \% ; \mathbf{\square})$ and represent the mean \pm SEM of at least three independent experiments each performed in quadruplicate (MTT) or sextuplicate (LDH). $* p<0.05, * * p<0.01, * * * p<0.001$ and $* * * * p<0.0001$ versus control response.
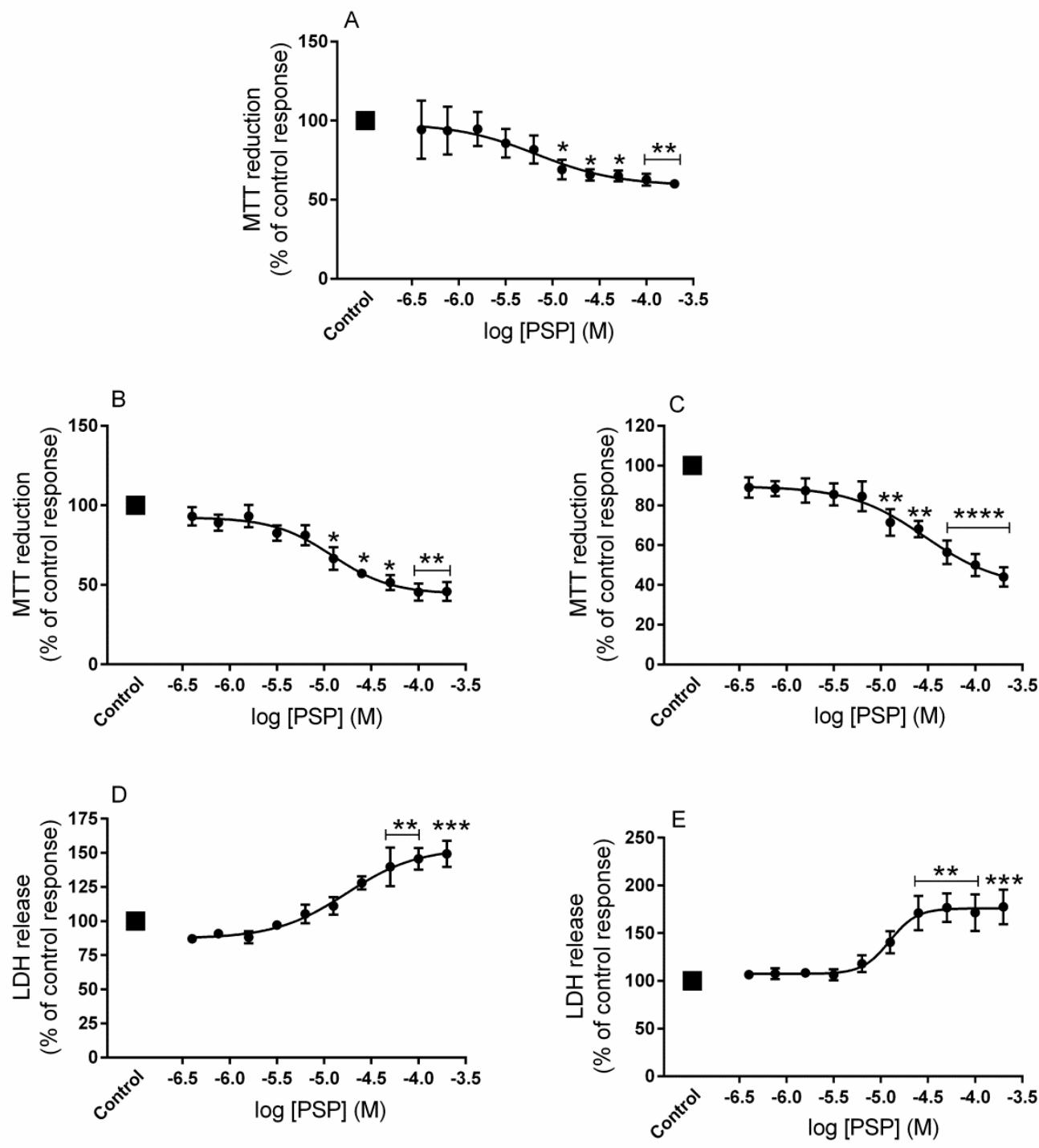